\title{
QUALIDADE DAS ÁGUAS DAS BACIAS HIDROGRÁFICAS DA CIDADE DE SALVADOR E DO MUNICÍPIO DE LAURO DE FREITAS, BAHIA
}

\section{HYDROGRAPHIC BASINS WATER QUALITY FROM THE CITIES OF SALVADOR AND LAURO DE FREITAS, BAHIA}

Juliana Jesus Santos

Bióloga. Mestranda na Universidade Federal da Bahia em Meio Ambiente, Águas e Saneamento. Instituto do Meio Ambiente e Recursos Hídricos. (juliana.santos@saeb.ba.gov.br)

\section{Ailton dos Santos Júnior}

Especialista em Recursos Hídricos. Coordenador do Monitoramento Ambiental do Instituto do Meio Ambiente e Recursos Hídricos. (ailton.junior@inema.ba.gov.br)

\section{Najara Santana Pita}

Mestranda na Universidade Federal da Bahia em Fisico-Química. Técnica em Meio Ambiente e Recursos Hídricos do Instituto do Meio Ambiente e Recursos Hídricos. (najara.pita@inema.ba.gov.br)

\section{Emily Karle dos Santos Conceição}

Mestranda na Universidade Federal da Bahia em Saúde Ambiente e Trabalho. Técnica em Meio Ambiente e Recursos Hídricos do Instituto do Meio Ambiente e Recursos Hídricos. (emily.conceicao@inema.ba.gov.br)

Valdinei Mauricio Batista Souza

Técnico em Meio Ambiente e Recursos Hídricos do Instituto do Meio Ambiente e Recursos Hídricos. (valdinei.souza@inema.ba.gov.br)

Aiane Catarina Fernandes Faria

Engenheira Ambiental. Instituto do Meio Ambiente e Recursos Hídricos. (aiane.faria@gmail.com)

\section{Resumo}

Os rios urbanos são parte de um complexo sistema, um espelho socioambiental das cidades. Os impactos causados à qualidade ambiental das águas dos rios urbanos impedem que os mesmos desempenhem suas funções ambientais, sociais, culturais e religiosas. As influências humanas na qualidade e no funcionamento adequado/natural dos sistemas hídricos, em prol do desenvolvimento urbano, despontam como as grandes responsáveis pelas condições atuais de suas águas. O objetivo principal deste trabalho foi avaliar o estado geral da qualidade das águas das Bacias Hidrográficas das cidades de Salvador e Lauro de Freitas, no estado da BA, a partir de duas abordagens complementares: o uso do Índice de Qualidade das Águas da National Sanitation Foundation e o Índice de Estado Trófico. Para a avaliação, foram selecionados ao menos três pontos em cada um dos principais rios de cada bacia, resultando num total de 47 pontos. Os pontos escolhidos estão dispostos da seguinte forma: um próximo à nascente, um próximo à foz e os demais, a meio curso. Esse delineamento permite realizar o acompanhamento da qualidade ao longo do rio. Os resultados do Índice da Qualidade da Água (IQA) e do Índice de Estado Trófico (IET) apresentaram cenários distintos para as Bacias Hidrográficas analisadas. Foi possível diagnosticar a perda progressiva da qualidade das águas da nascente para a foz em razão do aporte de efluentes domésticos oriundos das regiões mais densamente habitadas. Neste sentido, $70 \%$ dos mananciais foram diagnosticados para a qualidade ambiental como Ruim ou Péssimo, de acordo com o IQA. Quanto ao IET, todos os pontos apresentaram algum nível de eutrofização, mesmo aqueles que apresentaram boa qualidade. A maior parte, quase $50 \%$ dos trechos avaliados, apresentou eutrofização num estágio avançado (supereutrófico e/ou hipereutrófico), comprometendo assim seus usos múltiplos.

Palavras-chaves: Rios Urbanos, Qualidade Ambiental das Águas, Bacias Hidrográficas.

\section{Abstract}

The urban rivers are part of a complex system, some cities environmental-partner reflex. The impacts caused to the environmental quality of the water from the urban rivers prevent them from performing their duties environmental, social, cultural and religious. The human influence in the quality and the natural 
functioning of the water system - in favour of the urban development - emerge as the great responsible for the current water conditions. The main purpose of this study is evaluating the general state of water quality from the watersheds from cities of Salvador and Lauro de Freitas, in the state of Bahia, starting of two complementaries approaches: Water Quality Index, by National Sanitation Foundation and Trophic State Index. At least, three spots were chosen for valuation in each one of the most important rivers of each watershed - resulting in 47 spots. The spots chosen are arranged as follows: one near the source of the rivers, other near the mouth, and the others, mid-course. This design allows following the quality of the river. The results of the Water Quality Index (WQI) and of the Trophic State Index (TSI) and they presented different scenarios for the analyzed Hydrographic Basins. It was possible to diagnose the progressive loss of the quality of water from the source of the river to the mouth, due to the contribution of domestic effluents from the most densely populated regions. In this sense, $70 \%$ of the sources were diagnosed for environmental quality as Bad or Terrible, according to WQI. About the TSI, all the spots showed some level of eutrophication, even those that presented good quality. Most of it, almost $50 \%$ of the evaluated sections presented eutrophication in an advanced stage (supereutrophic and/or hypereutrophic), compromising their multiple uses.

Keywords: Urban rivers, water environmental quality, hydrographic basins

\section{INTRODUÇÂO}

As influências humanas na qualidade e no funcionamento adequado/natural dos sistemas hídricos, em prol do 'desenvolvimento urbano', despontam como as grandes responsáveis pelas condições atuais de suas águas. São os rios urbanos parte de um complexo sistema, um espelho socioambiental das cidades. Os impactos causados à qualidade ambiental das águas desses rios impedem que os mesmos desempenhem suas funções ambientais, sociais, culturais e religiosas.

Os mananciais exercem as funções de controle da temperatura e de regulação da incidência ou regime de chuvas, além de possibilitar a drenagem ou escoamento superficial das águas pluviais, e a natureza do uso e a ocupação do solo urbano têm uma grande interferência na qualidade das águas. Qualquer forma de uso impróprio do solo pode atentar alterações no meio aquático, a exemplo do aumento do escoamento superficial e a erosão, com o consequente assoreamento dos corpos d'água. Essas alterações influenciam as inundações nas cidades, favorecendo vários desastres urbanos, como os engarrafamentos e os deslizamentos, consequentemente causando o desabrigo de várias famílias que residem em áreas de planícies de inundações e às margens dos rios locais. Associadas a essa questão, podem-se ressaltar a redução das taxas de infiltração de água no solo e as diminuições dos níveis de água nos aquíferos, com a consequente alteração das vazões dos córregos urbanos. Estas questões passam despercebidas da população local e, infelizmente, dos que planejam e executam intervenções ou obras civis, os quais não levam em consideração os impactos associados aos rompimentos das condições de equilíbrio dinâmico nas áreas de influência das bacias urbanas (ROSSI et al., 2012).

Esgotos domésticos e efluentes industriais são considerados os principais contaminantes das águas superficiais, especialmente em áreas urbanas onde a água sofreu no último século crescente contaminação. Os principais fatores que colaboram para a poluição da água, além do lançamento de esgotos domésticos e efluentes industriais nos corpos hídricos, são a urbanização desenfreada, as atividades agrícolas e de mineração, os poluentes presentes na atmosfera carregados pela chuva, as mudanças climáticas, entre outros, os quais colocam em risco a existência de água para consumo na Terra.

Com isso, vale ressaltar um dos objetivos da Lei 9.433/1997 - Política Nacional dos Recursos Hídricos (PNRH) - qual seja, "assegurar à atual e às futuras gerações a necessária disponibilidade de água, em padrões de qualidade adequados aos respectivos usos" (BRASIL, 1997, p. 01). Entende-se que obter boa qualidade de água é o mesmo que não poluí-la, de forma a não comprometer a vida em todos os aspectos. Esta é, então, a principal finalidade da $\mathrm{PNRH}$, que só é possível através de uma utilização racional e integrada da água. Deve-se haver, portanto a disponibilidade equitativa do recurso hídrico, de forma que facilite o acesso de todos, ainda que em quantidade diferente (ZEITUM, 2009).

É indispensável que os planejadores e gestores municipais adotem providências quanto à expansão urbana desordenada ou mal 
planejada. Este trabalho técnico científico avalia a qualidade ambiental dos rios de 15 (quinze) bacias hidrográficas urbanas: Rio dos Seixos, Rio Ondina, Rio Lucaia, Rio Camarajipe, Rio das Pedras (e Pituaçu), Rio Passa Vaca, Rio Jaguaribe, Rio do Cobre, Rio Paraguari, Rio Ipitanga, Rio dos Macacos, Bacia Hidrográfica do Lobato, Bacia Hidrográfica do Rio Joanes, subbacias do Rio Ipitanga e do Rio Sapato. Essas bacias estão localizadas nos municípios de Salvador e Lauro de Freitas, no estado da Bahia.

É oportuno citar a Lei 9.433/1997 que inicia com as afirmações: "a água é um bem de domínio público" e "a água é um recurso natural limitado, dotado de valor econômico" (BRASIL, 1997, p. 01). Essa declaração do art. $1^{\circ}$, I e II, da lei em exame, é comentada por Paulo Affonso Leme Machado (2002, p. 39 e 55) da seguinte maneira: "a dominialidade pública da água, [...] não transforma o Poder Público federal ou estadual em proprietário da água, mas torna-o gestor desse bem, de interesse de todos", devendo, portanto, as esferas governamentais adotarem políticas que preservem as características naturais dos corpos hídricos, com finalidade também de conservar quantitativamente este bem. A água preserva 0 direito à vida da população, e negar água de boa qualidade e em quantidade satisfatória é o mesmo que condenála à morte (ONU, 2010).

Este trabalho tem como principal objetivo avaliar a qualidade das águas dos rios urbanos de Salvador e Lauro de Freitas.

\section{METODOLOGIA}

\subsection{DEFINIÇÃO DA REDE DE AMOSTRAGEM}

Para a determinação da localização dos pontos de coleta que compõem a malha amostral deste estudo, foram utilizados, preferencialmente, os pontos adotados nos estudos realizados pela Universidade Federal da Bahia - UFBA, publicados no livro "Caminho das Águas em Salvador - Bacias Hidrográficas, Bairros e Fontes" (SANTOS et al., 2010). Selecionaram-se ao menos três pontos em cada um dos principais rios de cada bacia, resultando num total de 54 pontos. Os pontos escolhidos estão dispostos da seguinte forma: um próximo à nascente, um próximo à foz e os demais, a meio curso. Esse delineamento permite realizar o acompanhamento da qualidade ao longo do rio.

\section{2. ÁREAS DE ESTUDO}

\subsubsection{SALVADOR}

São as seguintes as bacias hidrográficas do município de Salvador: Bacia Hidrográfica do Rio dos Seixos, Bacia Hidrográfica de Ondina, Bacia Hidrográfica do Rio Lucaia, Bacia Hidrográfica do Rio Camarajipe, Bacia Hidrográfica do Rio das Pedras (e Pituaçu), Bacia Hidrográfica do Rio Passa Vaca, Bacia Hidrográfica do Rio Jaguaribe, Bacia Hidrográfica do Rio do Cobre, Bacia Hidrográfica do Rio Paraguari, Bacia Hidrográfica do Rio Ipitanga, Bacia Hidrográfica do Rio dos Macacos, Bacia Hidrográfica do Lobato e a Subbacia Hidrográfica do Rio Sapato (Figura 1).

O Quadro 1 indica as coordenadas dos pontos a serem avaliados para as Bacias Hidrográficas.

\subsubsection{Bacia Hidrográfica do Rio dos Seixos}

O Rio dos Seixos é o principal rio dessa bacia. Suas nascentes se localizam no Vale do Canela e na Fonte Nossa Senhora da Graça, também conhecida como Fonte da Catarina. A partir daí, o rio segue pela Avenida Centenário até a foz, que se encontra próxima ao Morro do Cristo, na Barra. Todo o seu curso se encontra em áreas urbanizadas, sendo retificado em seu trecho inicial, e totalmente encapsulado na Avenida Centenário. É importante frisar que o rio é desviado para o sistema de esgotamento sanitário (captação em tempo seco) em uma estação na praia do Farol da Barra, próxima ao Morro do Cristo.

A Figura 2 mostra a representação do curso do Rio dos Seixos e as sugestões de pontos de coleta para esta bacia.

\subsubsection{Bacia Hidrográfica de Ondina}

Essa é a menor bacia de Salvador, correspondendo a apenas $1 \%$ do município. Fazem parte os bairros de Ondina, Calabar e Alto das Pombas, e as localidades de Jardim Apipema, Alto de Ondina e São Lázaro, bem como a Unidade de Conservação do Parque Zoobotânico Getulio Vargas. Ela possui quatro fontes: do Chega Nego, na Orla Atlântica, do Zoológico, do Chapéu de Couro, na entrada do Zoológico, e do Instituto de Biologia da UFBA.

A imagem da Figura 3 mostra a representação do curso dos rios que compõem essa bacia, assim como a sugestão de pontos. 
Figura 1: Malha amostral dos pontos dos rios de Salvador e Lauro de Freitas, Bahia

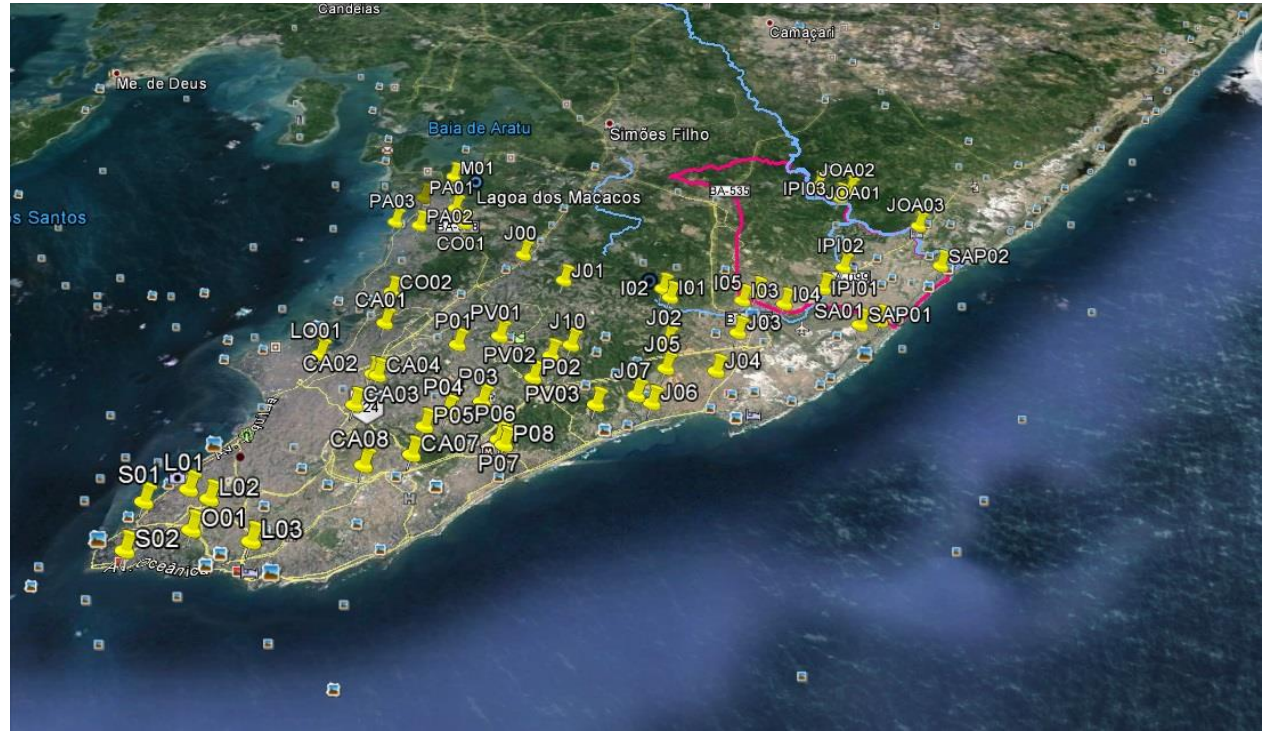

Fonte: Google Earth, 2015.

Quadro 1: Pontos, coordenadas, rios, localizações e ilustrações das Bacias Hidrográficas de Salvador e Lauro de Freitas, Bahia

\begin{tabular}{|c|c|c|c|}
\hline \multicolumn{4}{|c|}{ Salvador } \\
\hline Ponto & Coordenadas & Rio & Localização \\
\hline S01 & $\begin{array}{l}12^{\circ} 59^{\prime} 35.69^{\prime \prime} \mathrm{S} \\
38^{\circ} 31^{\prime} 29.49 " \mathrm{O}\end{array}$ & Rio dos Seixos & $\begin{array}{l}\text { Avenida Reitor Miguel Calmon, em } \\
\text { frente à FACED, Vale do Canela }\end{array}$ \\
\hline S02 & $\begin{array}{l}13^{\circ} 00^{\prime} 36.63^{\prime \prime} \mathrm{S} \\
38^{\circ} 31^{\prime} 27.92^{\prime \prime} \mathrm{O}\end{array}$ & Rio dos Seixos & $\begin{array}{l}\text { Foz do Rio Seixos - Morro do Cristo } \\
\text { (Barra) }\end{array}$ \\
\hline O01 & $\begin{array}{l}13^{\circ} 00^{\prime} 11.56^{\prime \prime S} \\
38^{\circ} 30^{\prime} 31.41 " \mathrm{O}\end{array}$ & Ondina & e \\
\hline L01 & $\begin{array}{l}12^{\circ} 59^{\prime} 19.50^{\prime \prime} \mathrm{S} \\
38^{\circ} 30^{\prime} 49.60^{\prime \prime} \mathrm{O}\end{array}$ & Rio Lucaia & $\begin{array}{l}\text { Próximo ao complexo de delegacias } \\
\text { dos Barris. No acesso à Secretaria de } \\
\text { Infraestrutura e Defesa Civil da } \\
\text { Prefeitura de Salvador }\end{array}$ \\
\hline L02 & $\begin{array}{l}12^{\circ} 59^{\prime} 31.70^{\prime \prime} \mathrm{S} \\
38^{\circ} 30^{\prime} 25.60^{\prime \prime} \mathrm{O}\end{array}$ & Rio Lucaia & $\begin{array}{c}\text { Avenida Anita Garibaldi, próximo ao } \\
\text { viaduto da Vasco da Gama.. }\end{array}$ \\
\hline L03 & $\begin{array}{l}13^{\circ} 00^{\prime} 26.15^{\prime \prime} \mathrm{S} \\
38^{\circ} 29^{\prime} 29.25^{\prime \prime} \mathrm{O}\end{array}$ & Rio Lucaia & $\begin{array}{c}\text { Rua Lucaia, em frente à ABAV } \\
\text { (Associação Brasileira de Agências de } \\
\text { Viagens da Bahia) }\end{array}$ \\
\hline CA01 & $\begin{array}{c}12^{\circ} 55^{\prime} 0.79 " \mathrm{~S} \\
38^{\circ} 28^{\prime} 19.56^{\prime \prime} \mathrm{O}\end{array}$ & Rio Camarajipe & $\begin{array}{c}\text { Alto do Cabrito, após o Dique de } \\
\text { Campinas (sob ponte) }\end{array}$ \\
\hline CA02 & $\begin{array}{l}12^{\circ} 56^{\prime} 28.7^{\prime \prime} \mathrm{S} \\
38^{\circ} 28^{\prime} 16.6^{\prime \prime} \mathrm{O}\end{array}$ & $\begin{array}{l}\text { Afluente do Rio } \\
\text { Camarajipe }\end{array}$ & Bom Juá, embaixo da BR 324 \\
\hline CA03 & $\begin{array}{l}12^{\circ} 57^{\prime} 17.4^{\prime \prime} \mathrm{S} \\
38^{\circ} 28^{\prime} 27.6^{\prime \prime} \mathrm{O}\end{array}$ & Rio Camarajipe & $\begin{array}{l}\text { R. Martiniano Bonfim (liga a Av. Barros } \\
\text { Reis à Av. Luis Eduardo Magalhães) }\end{array}$ \\
\hline CA04 & $\begin{array}{l}12^{\circ} 56^{\prime} 31.1^{\prime \prime} \mathrm{S} \\
38^{\circ} 28^{\prime} 11.1 " 1 " \mathrm{O}\end{array}$ & Rio Camarajipe & Av. Oliveira, Arraial do Retiro \\
\hline CA07 & $\begin{array}{l}12^{\circ} 58^{\prime} 30.77^{\prime \prime S} \\
38^{\circ} 27^{\prime} 13.44^{\prime \prime O}\end{array}$ & Rio Pernambués & $\begin{array}{c}\text { Av. Luis Viana, ao lado da Grande } \\
\text { Bahia }\end{array}$ \\
\hline CA08 & $\begin{array}{l}12^{\circ} 58^{\prime} 46.377^{\prime \prime S} \\
38^{\circ} 28^{\prime} 00.30^{\prime \prime O}\end{array}$ & Rio Camarajipe & Em frente à Rodoviária \\
\hline P01 & $\begin{array}{l}12^{\circ} 55^{\prime} 39.70 " \mathrm{~S} \\
38^{\circ} 26^{\prime} 49.10^{\prime \prime} \mathrm{O}\end{array}$ & Rio Pituaçu & $\begin{array}{c}\text { Final da Avenida Gal Costa, no fundo } \\
\text { da Penitenciária Lemos de Brito }\end{array}$ \\
\hline P02 & $\begin{array}{l}12^{\circ} 56^{\prime} 34.30^{\prime \prime S} \\
38^{\circ} 25^{\prime} 17.90^{\prime \prime O}\end{array}$ & Rio Pituaçu & $\begin{array}{c}\text { Antes da estação elevatória, final da } \\
\text { Bacia Alto Pituaçu. Embasa - Vila } \\
\text { Nova de Pituaçu }\end{array}$ \\
\hline P03 & $\begin{array}{l}12^{\circ} 57^{\prime} 12.50 " \mathrm{~S} \\
38^{\circ} 26^{\prime} 9.80^{\prime \prime O}\end{array}$ & Rio Cachoeirinha & $\begin{array}{c}\text { Acesso pela R. Recanto da } \\
\text { Cachoeirinha - Cabula IV, atrás do }\end{array}$ \\
\hline
\end{tabular}




\begin{tabular}{|c|c|c|c|}
\hline & & & posto de saúde \\
\hline P04 & $\begin{array}{l}12^{\circ} 57^{\prime} 29.00 " \mathrm{~S} \\
38^{\circ} 26^{\prime} 45.50^{\prime \prime} \mathrm{O}\end{array}$ & Rio Saboeiro & Dique do Saboeiro \\
\hline P05 & $\begin{array}{l}12^{\circ} 57^{\prime} 50.00 " \mathrm{~S} \\
38^{\circ} 27^{\prime} 6.40^{\prime \prime} \mathrm{O}\end{array}$ & Rio Cascão & $\begin{array}{l}\text { 19º Batalhão de Caçadores, antes do } \\
\text { Dique do Cascão }\end{array}$ \\
\hline P06 & $\begin{array}{c}12^{\circ} 58^{\prime} 8.80^{\prime \prime S} \\
38^{\circ} 25^{\prime} 45.30 " \mathrm{O}\end{array}$ & Rio das Pedras & $\begin{array}{c}\text { Encontro da Avenida Jorge Amado com } \\
\text { a Alameda das Acácias }\end{array}$ \\
\hline P07 & $\begin{array}{c}12^{\circ} 58^{\prime} 7.73^{\prime \prime S} \\
38^{\circ} 25^{\prime} 41.39^{\prime \prime O}\end{array}$ & Saboeiro & Av. Jorge Amado, próximo à Rede Mix \\
\hline P08 & $\begin{array}{l}12^{\circ} 58^{\prime} 16.60 " \mathrm{~S} \\
38^{\circ} 25^{\prime} 39.20 " \mathrm{O}\end{array}$ & Rio das Pedras & $\begin{array}{c}\text { Ponte de Ferro, próximo à Bolandeira, } \\
\text { acesso pela Av. Jorge Amado }\end{array}$ \\
\hline PV00 & $\begin{array}{l}12^{\circ} 57^{\prime} 16.50^{\prime \prime} \mathrm{S} \\
38^{\circ} 24^{\prime} 5.80^{\prime \prime} \mathrm{O}\end{array}$ & Rio Passa Vaca & ( \\
\hline PV03 & $\begin{array}{l}12^{\circ} 57^{\prime} 16.50^{\prime \prime} \mathrm{S} \\
38^{\circ} 24^{\prime} 5.80^{\prime \prime} \mathrm{O}\end{array}$ & Rio Passa Vaca & Av. Ibirapitanga, guarita do GreenVille \\
\hline J01 & $\begin{array}{l}12^{\circ} 53^{\prime} 40.60 " \mathrm{~S} \\
38^{\circ} 24^{\prime} 56.10^{\prime \prime O}\end{array}$ & Rio Jaguaribe & $\begin{array}{c}\text { Via coletora três, a montante da lagoa } \\
\text { de estabilização (Cajazeiras) }\end{array}$ \\
\hline $\mathrm{J} 02$ & $\begin{array}{l}12^{\circ} 55^{\prime} 31.84 " \mathrm{~S} \\
38^{\circ} 22^{\prime} 49.33^{\prime \prime O}\end{array}$ & Rio Jaguaribe & $\begin{array}{l}\text { Av. Paralela, próximo à entrada da Av. } \\
\text { Orlando Gomes }\end{array}$ \\
\hline J03 & $\begin{array}{l}12^{\circ} 55^{\prime} 16.76 " \mathrm{~S} \\
38^{\circ} 21^{\prime} 27.24 " \mathrm{O}\end{array}$ & Córrego do Bispo & $\begin{array}{c}\text { Av. Paralela, próximo à Estação } \\
\text { Mussurunga }\end{array}$ \\
\hline J04 & $\begin{array}{l}12^{\circ} 56^{\prime} 23.10^{\prime \prime S} \\
38^{\circ} 21^{\prime} 54.20^{\prime \prime} \mathrm{O} \\
\end{array}$ & Córrego do Bispo & $\begin{array}{l}\text { Rua Beira Rio (Nova Brasília - } \\
\text { Itapuã).Ponto sob ponte }\end{array}$ \\
\hline J05 & $\begin{array}{l}12^{\circ} 56^{\prime} 18.20^{\prime \prime S} \\
38^{\circ} 22^{\prime} 50.50^{\prime \prime} \mathrm{O}\end{array}$ & Rio Mangabeira & $\begin{array}{c}\text { Acesso pela Av. Orlando Gomes, Rua } \\
\text { da Gratidão ( } 2^{\underline{a}} \text { ponte) }\end{array}$ \\
\hline J06 & $\begin{array}{l}12^{\circ} 57^{\prime} 13.79 " \mathrm{~S} \\
38^{\circ} 23^{\prime} 5.32^{\prime \prime} \mathrm{O}\end{array}$ & Rio Jaguaribe & $\begin{array}{l}\text { Final da Av. Orlando Gomes (próximo à } \\
\text { orla) - acesso à Av. Otávio Mangabeira }\end{array}$ \\
\hline J07 & $\begin{array}{r}12^{\circ} 57^{\prime} 1.80 " \mathrm{~S} \\
38^{\circ} 23^{\prime} 22.60^{\prime \prime O}\end{array}$ & Rio Trobogy & Rua da Adutora \\
\hline $\mathrm{J} 10$ & $\begin{array}{l}12^{\circ} 55^{\prime} 39.57^{\prime} \mathrm{S} \\
38^{\circ} 24^{\prime} 39.30^{\prime \prime} \mathrm{O}\end{array}$ & Rio Mocambo & Acesso pela Rua Mocambo \\
\hline J11 & $\begin{array}{l}12^{\circ} 55^{\prime} 23.70 " \mathrm{~S} \\
38^{\circ} 26^{\prime} 2.70^{\prime \prime} \mathrm{O}\end{array}$ & Rio Trobogy & $\begin{array}{c}\text { Rua Jurema Santos (atrás da Via } \\
\text { Regional), acesso próximo à } \\
\text { borracharia }\end{array}$ \\
\hline J12 & $\begin{array}{l}12^{\circ} 55^{\prime} 57.20^{\prime \prime S} \\
38^{\circ} 25^{\prime} 0.90^{\prime \prime} \mathrm{O}\end{array}$ & Rio Trobogy & $\begin{array}{l}\text { Vale dos Lagos. Acesso ao lado da TL } \\
\text { Material de Construção, ao lado do } \\
\text { campo de futebol }\end{array}$ \\
\hline CO01 & $\begin{array}{l}12^{\circ} 51^{\prime} 41.90 " \mathrm{~S} \\
38^{\circ} 27^{\prime} 12.90 " \mathrm{O}\end{array}$ & Rio do Cobre & $\begin{array}{c}\text { Fazenda Coutos, Estrada da Base } \\
\text { Naval de Aratu, entrada do acesso ao } \\
\text { Hospital do Subúrbio }\end{array}$ \\
\hline CO02 & $\begin{array}{c}12^{\circ} 54 ' 2.60^{\prime \prime} \mathrm{S} \\
38^{\circ} 28^{\prime} 21.90^{\prime \prime}\end{array}$ & Rio do Cobre & $\begin{array}{l}\text { Rua do Cabrito, sobre a ponte (São } \\
\text { João do Cabrito) }\end{array}$ \\
\hline PA01 & $\begin{array}{l}12^{\circ} 51^{\prime} 6.30^{\prime \prime} \mathrm{S} \\
38^{\circ} 27^{\prime} 29.9^{\prime \prime} \mathrm{O}\end{array}$ & Rio Paraguari & Vista Alegre \\
\hline PA02 & $\begin{array}{l}12^{\circ} 51^{\prime} 43.40 " \mathrm{~S} \\
38^{\circ} 28^{\prime} 11.20 " \mathrm{O} \\
\end{array}$ & Rio Paraguari & Rua da Glória (ponte) \\
\hline PA03 & $\begin{array}{l}12^{\circ} 51 \text { '35.80"S } \\
38^{\circ} 28^{\prime} 43.60^{\prime \prime O}\end{array}$ & Rio Paraguari & Suburbana, antes da linha do trem \\
\hline 101 & $\begin{array}{l}12^{\circ} 54^{\prime} 12.81^{\prime \prime S} \\
38^{\circ} 22^{\prime} 46.41^{\prime \prime O}\end{array}$ & Riacho Tapuá Mirim & Fazenda Grande IV \\
\hline 102 & $\begin{array}{l}12^{\circ} 53^{\prime} 56.46^{\prime \prime} \mathrm{S} \\
38^{\circ} 22^{\prime} 55.49^{\prime \prime} \mathrm{O}\end{array}$ & Rio Ipitanga & Logo depois da Barragem Ipitanga I \\
\hline 103 & $\begin{array}{l}12^{\circ} 54^{\prime} 17.62^{\prime \prime S} \\
38^{\circ} 21^{\prime} 19.76^{\prime \prime O}\end{array}$ & Rio Ipitanga & Sob a rodovia CIA Aeroporto \\
\hline 104 & $\begin{array}{l}12^{\circ} 54^{\prime} 24.23^{\prime \prime} \mathrm{S} \\
38^{\circ} 20^{\prime} 29.98^{\prime \prime O}\end{array}$ & Rio Ipitanga & Aeroporto \\
\hline 105 & $\begin{array}{l}12^{\circ} 54^{\prime} 02.43^{\prime \prime S} \\
38^{\circ} 21^{\prime} 02.36^{\prime \prime} \mathrm{O}\end{array}$ & Rio Itinga & Jardim das Margaridas \\
\hline M01 & $\begin{array}{l}12^{\circ} 49^{\prime} 56.3^{\prime \prime} \mathrm{S} \\
38^{\circ} 27^{\prime} 18.9^{\prime \prime O}\end{array}$ & Rio dos Macacos & $\begin{array}{l}\text { Junto à represa dos Macacos na base } \\
\text { naval }\end{array}$ \\
\hline M02 & $12^{\circ} 49^{\prime} 49.30 " \mathrm{~S}$ & Rio dos Macacos & Sob rodovia \\
\hline
\end{tabular}




\begin{tabular}{|c|c|c|c|}
\hline \multicolumn{4}{|c|}{$38^{\circ} 27^{\prime} 43.01^{\prime \prime O}$} \\
\hline \multicolumn{4}{|c|}{ Lauro de Freitas } \\
\hline Ponto & Coordenadas & Rio & Localização \\
\hline SA01 & $\begin{array}{l}12^{\circ} 54^{\prime} 44.1^{\prime \prime} \mathrm{S} \\
38^{\circ} 18^{\prime} 32,1^{\prime \prime O}\end{array}$ & Rio Sapato & $\begin{array}{l}\text { Sob ponte na rua asfaltada, Bairro } \\
\text { Ipitanga }\end{array}$ \\
\hline SAP02 & $\begin{array}{l}-12.903349 \\
-38.300573 \\
\end{array}$ & Rio Sapato & $\begin{array}{c}\text { Cruzamento das Ruas Elza Paranhos e } \\
\text { Elho Brito }\end{array}$ \\
\hline SAP03 & $\begin{array}{l}-12.885582 \\
-38.286445 \\
\end{array}$ & Rio Sapato & $\begin{array}{c}\text { Cruzamento da Rua Praia de Tambu e } \\
\text { Av. Praia da Copa }\end{array}$ \\
\hline LO01 & $\begin{array}{l}12^{\circ} 55^{\prime} 53.59 " \mathrm{~S} \\
38^{\circ} 29^{\prime} 23.81 " \mathrm{O}\end{array}$ & Lobato & Próximo ao posto de gasolina BR \\
\hline JOA01 & $\begin{array}{l}12^{\circ} 50^{\prime} 11.09^{\prime \prime} \\
38^{\circ} 19^{\prime} 27.42^{\prime \prime}\end{array}$ & Barragem Joanes I & $\begin{array}{l}\text { Sob o pontilhão sobre a Barragem } \\
\text { Joanes I, próximo ao povoado de } \\
\text { Capelão no município de Lauro de } \\
\text { Freitas }\end{array}$ \\
\hline JOA02 & $\begin{array}{l}12^{\circ} 50^{\prime} 22.86^{\prime \prime} \\
38^{\circ} 18^{\prime} 46.39^{\prime \prime}\end{array}$ & Joanes & $\begin{array}{l}\text { A jusante da Barragem Joanes I, dentro } \\
\text { do Condomínio Águas do Joanes, na } \\
\text { via a esquerda, entrando na segunda } \\
\text { cancela e seguindo o caminho até o rio }\end{array}$ \\
\hline JOA03 & $\begin{array}{l}12^{\circ} 51^{\prime} 44.20^{\prime \prime} \\
38^{\circ} 17^{\prime} 26.00^{\prime \prime}\end{array}$ & Joanes & $\begin{array}{l}\text { Sob a ponte na margem direita da } \\
\text { rodovia BA-099 sobre o rio Joanes, } \\
\text { próximo ao Centro de Convenção } \\
\text { Marina Riverside e ao Terminal Mãe } \\
\text { Mirinha de Portão, em ambiente lótico e } \\
\text { área de elevado nível de urbanização }\end{array}$ \\
\hline IPI01 & $\begin{array}{l}-12.898426 \\
-38.328044\end{array}$ & Ipitanga & $\begin{array}{l}\text { Rua Euvaldo Santos Leite, próximo ao } \\
\text { ginásio municipal de esportes de Lauro } \\
\text { de Freitas }\end{array}$ \\
\hline IPI02 & $\begin{array}{l}-12.88667800 \\
-38.32008300\end{array}$ & Ipitanga & $\begin{array}{c}\text { Sob a ponte na BA-099 (Estrada do } \\
\text { Coco), situada em frente ao depósito } \\
\text { central das lojas Insinuante, próximo a } \\
\text { uma torre de telefonia celular }\end{array}$ \\
\hline IPI03 & $\begin{array}{l}-12.844400 \\
-38.317212 \\
\end{array}$ & Ipitanga & $\begin{array}{c}\text { Rua Celso Alves, dentro de um } \\
\text { condomínio }\end{array}$ \\
\hline
\end{tabular}

Fonte: Os Autores, 2017.

\subsubsection{Bacia Hidrográfica do Rio Lucaia}

O principal rio dessa bacia tem sua nascente na Avenida Joana Angélica, passando pelo Dique do Tororó e seguindo por todo canteiro central da Avenida Vasco da Gama, hoje encapsulado, desaguando no Largo da Mariquita, no Rio Vermelho. O Dique do Tororó recebeu, por muitos anos, descargas de esgotos sanitários, causando sua eutrofização e a morte de muitos organismos. Atualmente, todos esses pontos de lançamento de esgotos foram eliminados e processos de revitalização o transformaram em um dos pontos turísticos da capital.

A Figura 4 mostra os principais cursos d'água desta bacia e os possíveis locais de coleta. Seu trecho encapsulado, na Avenida Vasco da Gama, encontra-se destacado em um tom mais claro.

\subsubsection{Bacia Hidrográfica do Rio Camarajipe}

A Bacia Hidrográfica do Rio Camarajipe está entre as três maiores bacias do município, cujo rio principal nasce próximo a Pirajá, passa pela região do Iguatemi até desaguar no bairro do Costa Azul, percorrendo $14 \mathrm{~km}$. Seu curso percorre, inicialmente (próximo à nascente), áreas carentes de infraestrutura urbana, o que compromete a qualidade da água. Além disso, esse rio corta a cidade em regiões de grande fluxo de pessoas, carros etc, onde se pode notar a influência antrópica nesse corpo d'água. O Rio Camarajipe ainda é utilizado como corpo receptor de esgotos sanitários, e, nas imediações do Shopping Center Iguatemi, é desviado para o sistema de esgotamento da cidade (captação em tempo seco). Além disso, parte de seu leito foi retificada, uma represa foi construída no alto do Cabrito (formando o Dique de Campinas) e sua foz modificada, do Largo da Mariquita, no Rio Vermelho, para o bairro do Costa Azul. Assim também aconteceu com seus afluentes, como o 
Rio das Tripas, que está encapsulado em grande parte do seu curso, e o Rio Campinas, que se encontra totalmente canalizado.
A Figura 5 mostra o curso do Rio Camarajipe e do Rio das Tripas (em seu trecho visível) e os locais de coleta.

Figura 2: Curso d'água do Rio dos Seixos, Salvador-BA

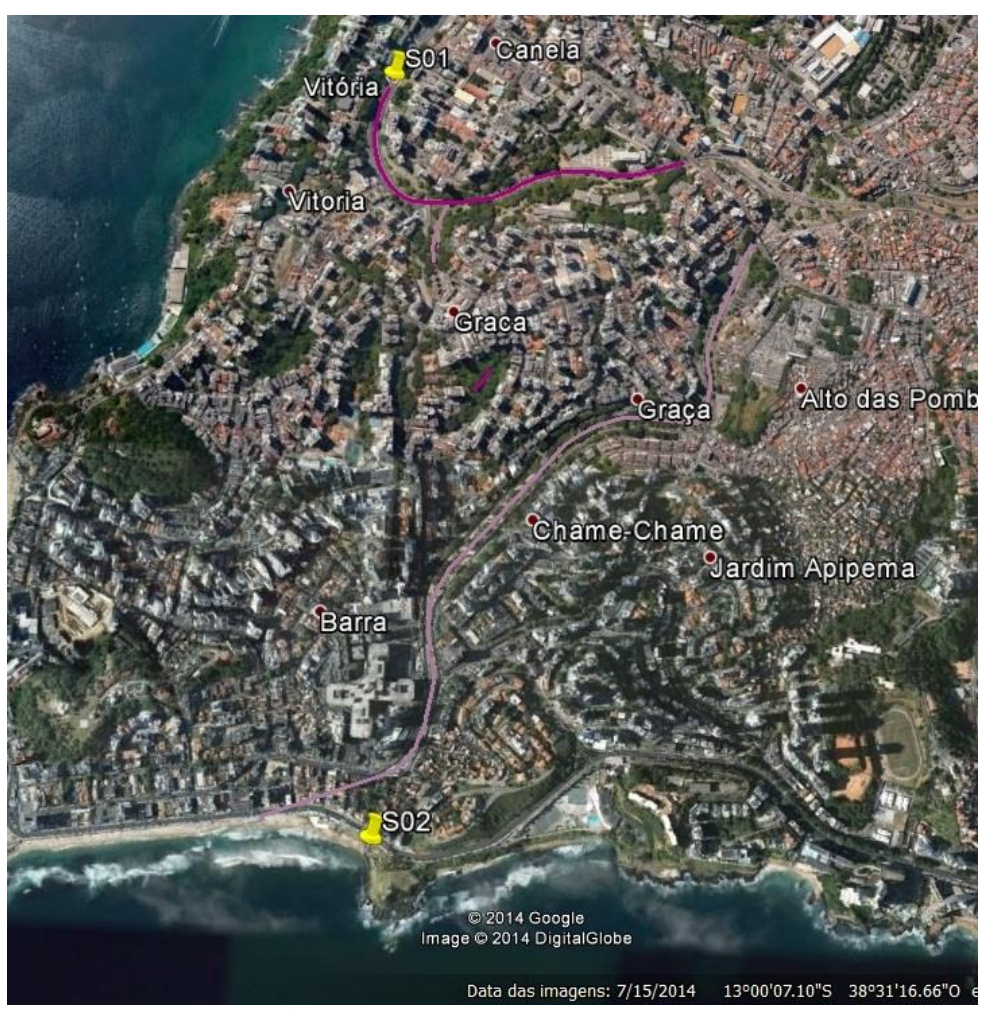

Fonte: INEMA, 2013/2014.

Figura 3: Curso d'água da bacia hidrográfica de Ondina, Salvador-BA

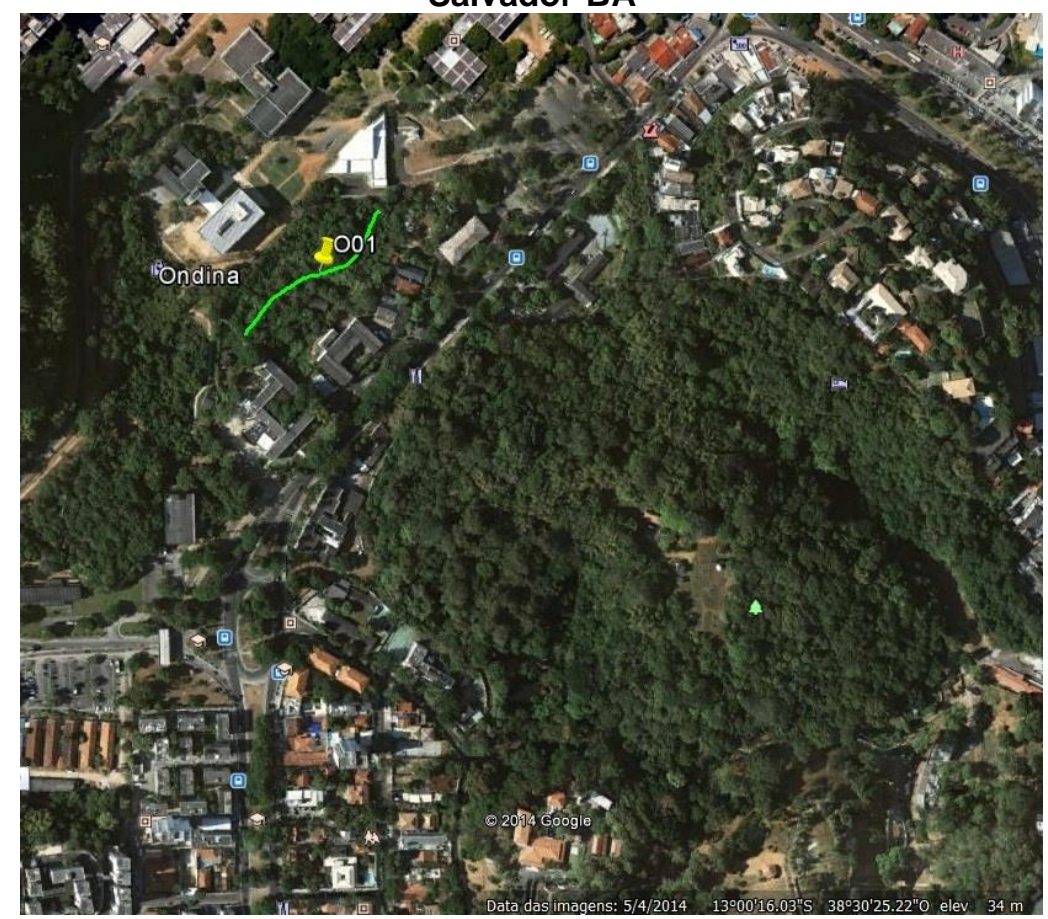

Fonte: INEMA, 2013/2014. 
Figura 4: Curso d'água da bacia hidrográfica do rio Lucaia, Salvador-BA

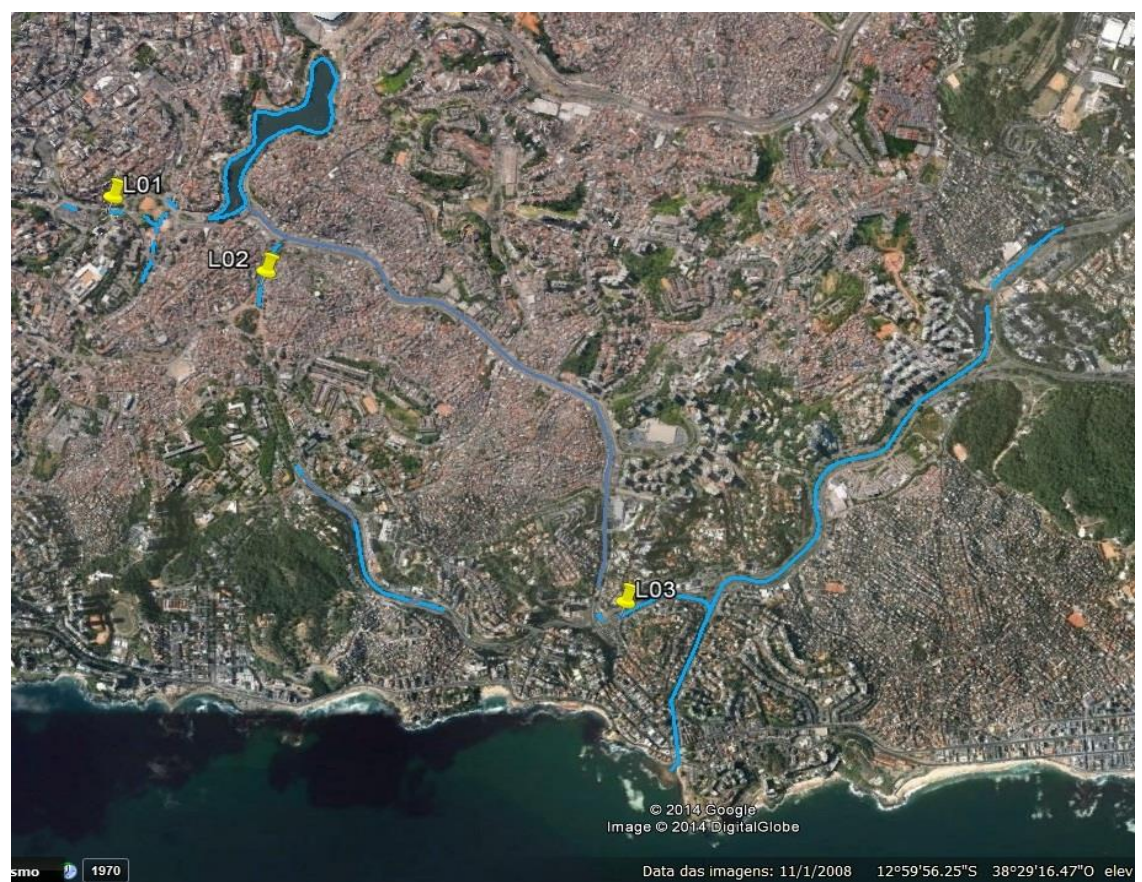

Fonte: INEMA, 2013/2014.

Figura 5: Curso d'água da bacia hidrográfica do rio Camarajipe, Salvador-BA.

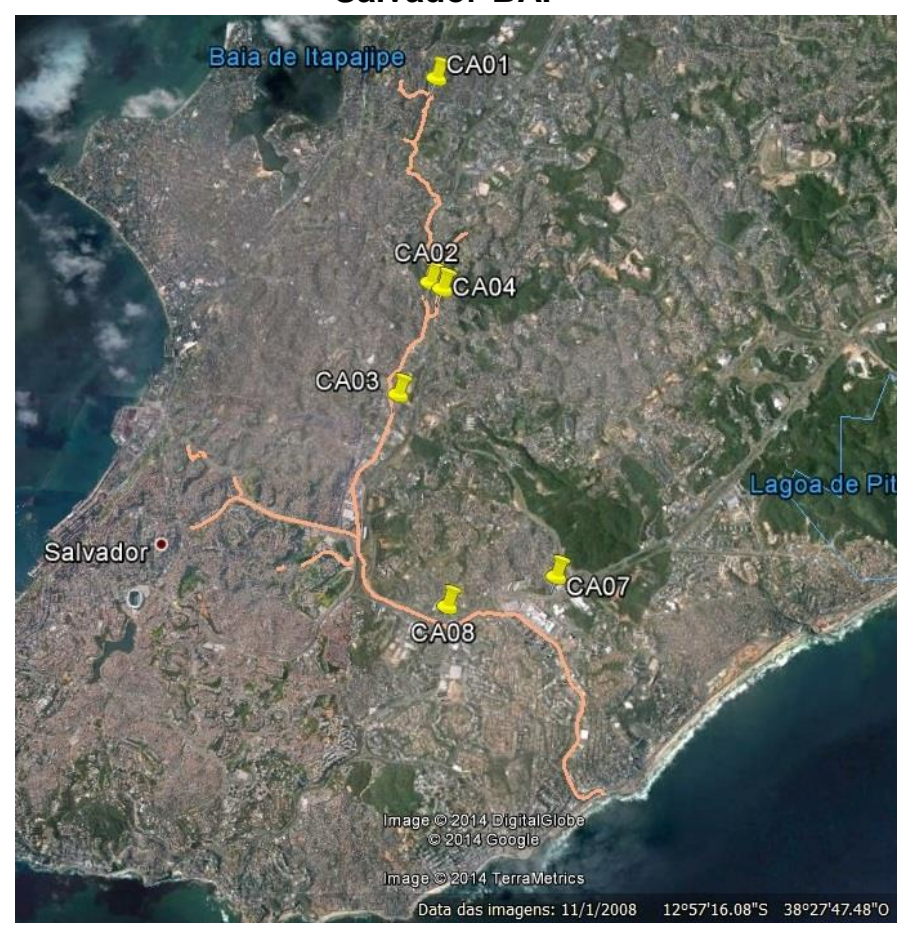

Fonte: INEMA, 2013/2014.

\subsubsection{Bacia Hidrográfica Pedras/Pituaçu}

A Bacia do Rio das Pedras inclui os Rios Pituaçu, Cachoeirinha, Saboeiro, Cascão e o Rio das Pedras. Este é formado a partir da confluência dos demais. O Rio Saboeiro nasce na região do Cabula VI e segue em direção ao Imbuí. O Rio Cascão nasce numa área de proteção ambiental pertencente ao 19ํㅡㄹ Batalhão de Caçadores - 19 BC -, portanto, seu trecho inicial se encontra fora das áreas de grande pressão demográfica. Entretanto, o Rio Cascão também segue em direção ao bairro do Imbuí, onde se encontra com o Rio Saboeiro, formando - Rio das Pedras, hoje encapsulado. O Rio Cachoeirinha nasce no bairro de Sussuarana, e o Rio Pituaçu, maior e principal afluente da Bacia 
do Rio das Pedras, tem suas cabeceiras próximas à BR-324. Os Rios das Pedras e Pituaçu, por sua vez, se encontram nas proximidades da Avenida Jorge Amado, seguindo juntos com o nome de Rio das Pedras, até a foz, na praia da Boca do Rio. É bom salientar que o Rio Pituaçu é desviado para a rede do sistema de esgotamento na altura da comunidade de Vila Nova de Pituaçu, antes da Lagoa de Pituaçu.

No mapa da Figura 6, estão representados os cursos dos rios Pituaçu, Cachoeirinha, Saboeiro, Cascão e Rio das Pedras, e seus pontos. Os trechos no tom mais escuro se encontram encapsulados.

\section{Figura 6: Curso d'água da bacia hidrográfica do rio das Pedras (Pituaçu), Salvador-BA}

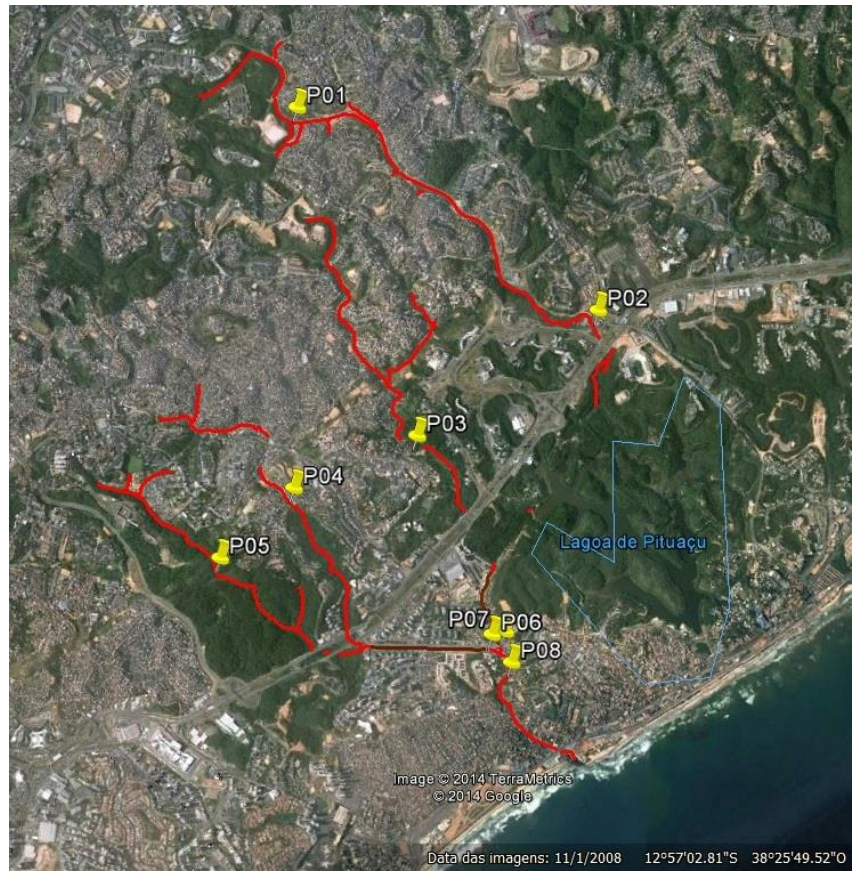

Fonte: INEMA, 2013/2014.

\subsubsection{Bacia Hidrográfica do Rio Passa Vaca}

O Rio Passa Vaca nasce no bairro de São Rafael, é sobreposto pela Av. Paralela e atravessa todo 0 bairro de Patamares, desaguando no mesmo estuário que o Rio Jaguaribe. Na sua foz, encontra-se o Parque do Manguezal do Passa Vaca, uma APP - Área de Preservação Permanente - implantada por meio do Decreto n. 19.752, de 13/07/2009 (SALVADOR, 2009). Apesar disso, o Rio Passa Vaca também sofre com 0 processo de urbanização do município e vem sendo degradado pelo lançamento de esgotos e resíduos sólidos de loteamentos e assentamentos irregulares, comprometendo, consequentemente, o manguezal e todos os ecossistemas a ele associados.

O curso do Rio Passa Vaca está representado na Figura 7, assim como o ponto de coleta nesse rio.

\subsubsection{Bacia Hidrográfica do Rio Jaguaribe}

O Rio Jaguaribe nasce nos bairros de Águas Claras, Valéria e Castelo Branco, passando pelo Jardim Nova Esperança, Cajazeiras VIII, Nova Brasília, Trobogy, Mussurunga e Bairro da Paz, e deságua em Piatã, percorrendo 15,2 km. Apresenta vários afluentes com grande vazão, como os rios Trobogy e Mangabeira. A área de drenagem dessa bacia se caracteriza por ser densamente povoada e, geralmente, com infraestrutura urbana precária, o que compromete a qualidade dos rios. Além disso, o antigo "lixão", atualmente aterro controlado de resíduos sólidos de Canabrava, também apresenta potencial de contaminação desses mananciais.

Sendo assim, os pontos de coleta se localizam não só no rio principal, mas nos seus principais afluentes, conforme a imagem da Figura 8.

\subsubsection{Bacia Hidrográfica do Rio do Cobre}

O Rio do Cobre tem sua principal nascente na Lagoa da Paixão, no bairro Moradas da Lagoa, um afluente no Dique de Campinas (Dique do Cabrito) e apresenta um barramento, a Represa 
do Cobre, que já foi um importante manancial de abastecimento, sendo uma área protegida como "Parque Florestal da Represa do Cobre". Além deste Parque, a bacia do Cobre está inserida em outras Unidades de Conservação, como a APA da Bacia do Cobre / São Bartolomeu, o Parque Metropolitano de Pirajá e o Parque Municipal de
São Bartolomeu. Entretanto, sua foz se encontra na Enseada do Cabrito, onde as pressões urbanas são maiores, comprometendo, portanto, a qualidade das águas no seu curso final.

A Figura 9 mostra o curso do Rio do Cobre desde a sua nascente, na Lagoa da Paixão, até a foz na enseada do cabrito.

Figura 7: Curso d'água da bacia hidrográfica do rio Passa Vaca, Salvador-BA

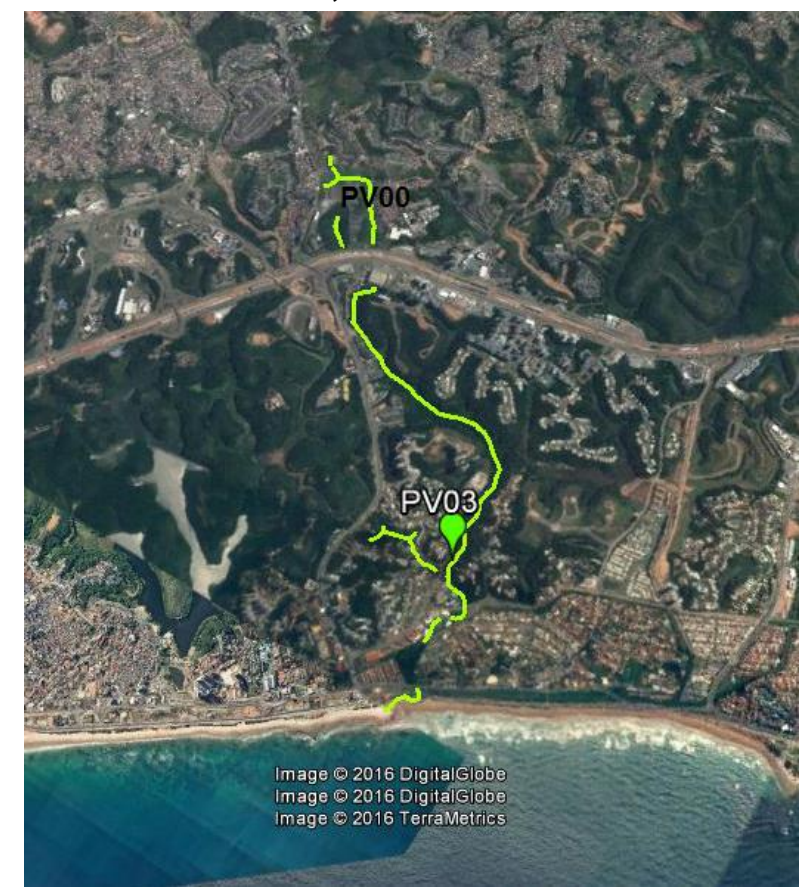

Fonte: INEMA, 2013/2014

Figura 8: Curso d'água da bacia hidrográfica do rio Jaguaribe, Salvador-BA

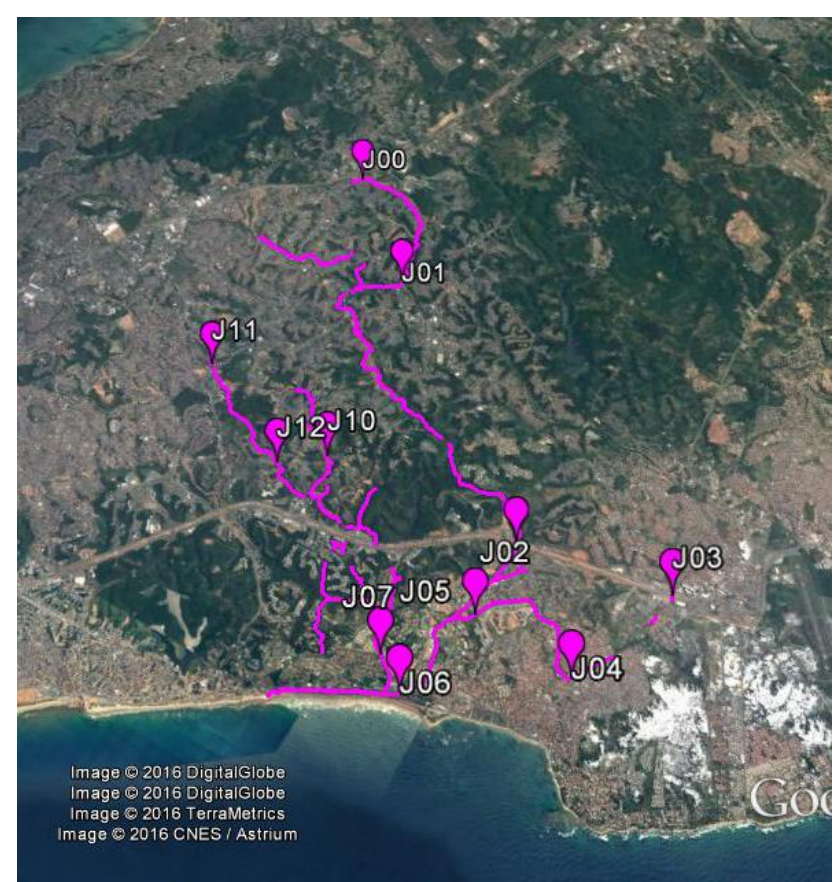

Fonte: INEMA, 2013/2014. 


\section{Figura 9: Curso d'água da bacia hidrográfica do rio do Cobre, Salvador-BA}

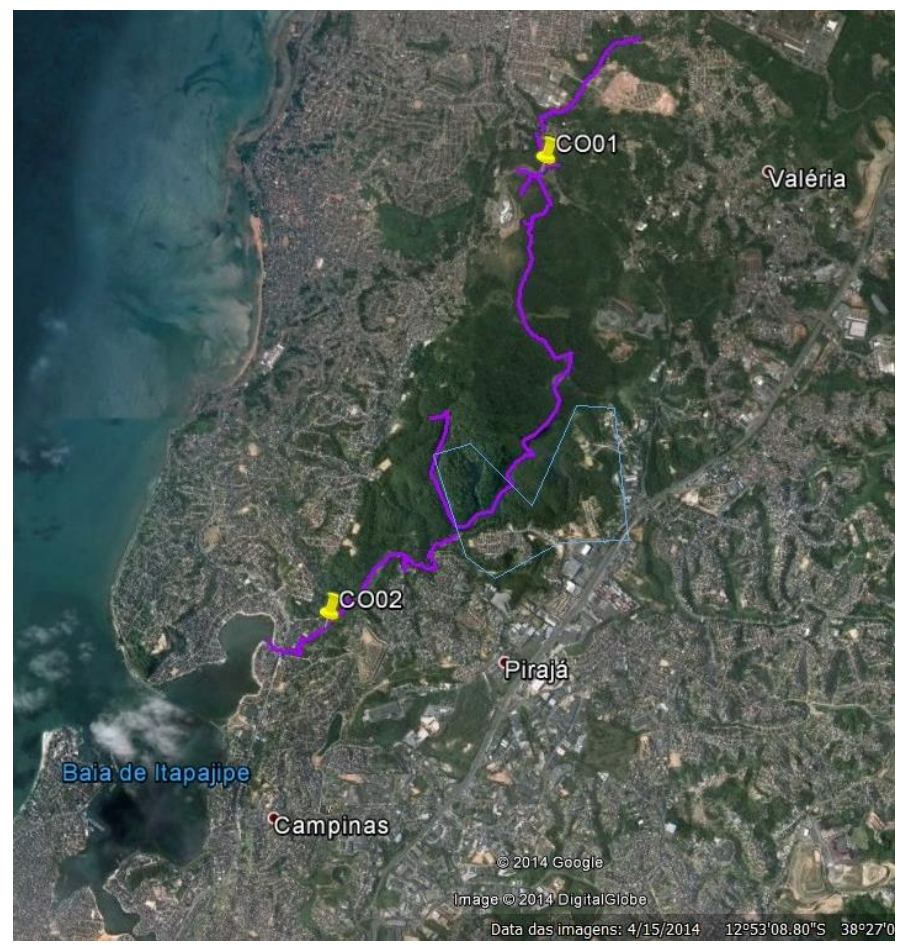

Fonte: INEMA, 2013/2014.

\subsubsection{Bacia Hidrográfica do Rio Paraguari}

O principal rio dessa bacia nasce na região da Estrada Velha de Periperi, em Coutos, e deságua na praia de Periperi. Seu curso passa por áreas de ocupação espontânea, com construções sobre o rio e sem sistema de esgotamento sanitário. Sendo assim, excretas humanas e esgotos sanitários são lançados diretamente na água, comprometendo a qualidade da mesma. O curso do Rio Paraguari está representado na Figura 10.

\section{Figura 10: Curso d'água da bacia hidrográfica do rio do Paraguari, Salvador-BA}

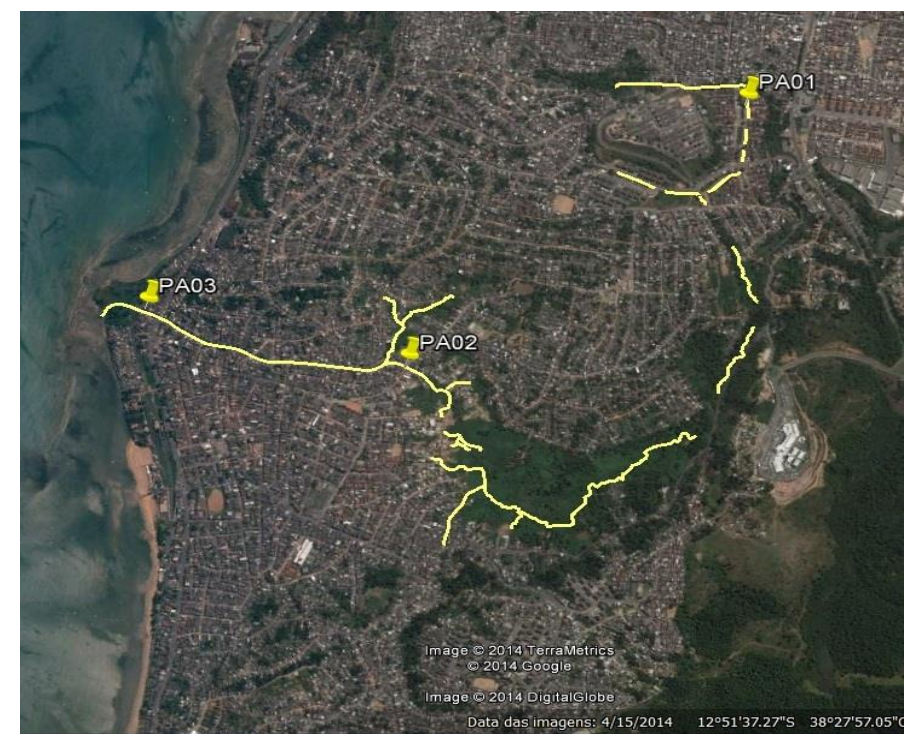

Fonte: INEMA, 2013/2014. 


\subsubsection{Bacia Hidrográfica do Rio Ipitanga}

O Rio Ipitanga possui três barramentos para o abastecimento humano: as Represas Ipitanga I, II e III. Este rio é a sub-bacia do Rio Joanes, formando o sistema de barragens JoanesIpitanga. Ele nasce no município de Simões Filho, em Pitanguinha, próximo à Represa Ipitanga III. Em Salvador, passa pelos bairros de Nova Esperança, Cassange, Cajazeiras XI, Fazenda Grande II, Boca da Mata, São Cristovão, Jardim das Margaridas, Itinga e Aeroporto. Essa bacia sofre forte pressão por moradia e expansão da mineração por pedreiras e cascalheiras, mas apresenta cobertura vegetal compatível com as áreas de proteção dos mananciais. Em sua área de abrangência, há duas unidades de conservação: a APA Joanes-Ipitanga - instituída pelo Decreto Estadual n. 7.596 de 05/06/1999 (BAHIA, 1999) -, e o Parque Ipitanga I. O rio deságua a jusante da barragem Joanes $\mathrm{I}$, em área declarada como de proteção de mananciais, pela Lei Estadual n. 3.858/80 (BAHIA, 1980).

A Figura 11 apresenta 0 curso do Rio Ipitanga, assim como os pontos de amostragem para esse rio.

\section{Figura 11: Curso d'água da bacia hidrográfica do rio Ipitanga, Salvador-BA}

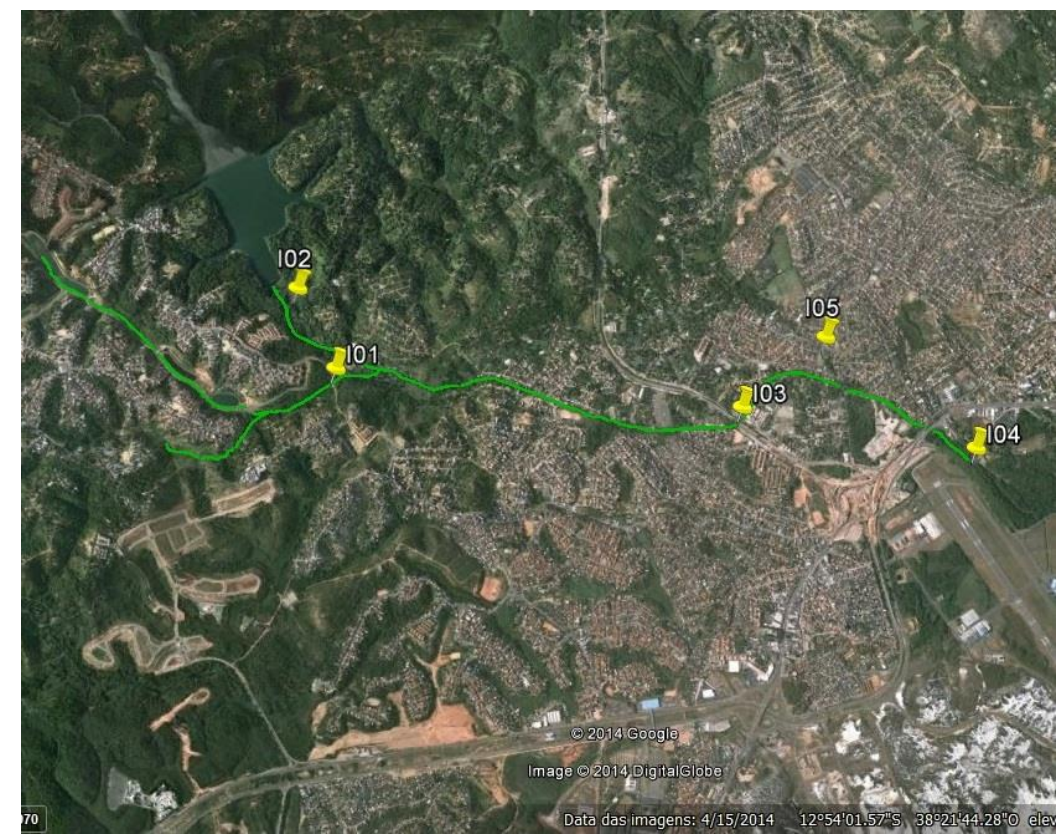

Fonte: INEMA, 2013/2014.

\subsubsection{Bacia Hidrográfica do Rio dos Macacos}

O Rio dos Macacos faz divisa entre o município de Simões Filho e Salvador, e deságua na Baía de Aratu. Possui um barramento, a represa dos Macacos, dentro de área militar. Nessa bacia, estão o Quilombo dos Macacos e a Vila Militar da Marinha, base de Aratu. Além disso, um córrego que nasce em Paripe deságua no rio principal dessa bacia, despejando esgotos sanitários no seu curso.

A Figura 12 apresenta o curso do Rio dos Macacos e os pontos de coleta para esse rio.

\subsubsection{Bacia Hidrográfica do Rio Sapato}

O Rio Sapato tem nascente na região de dunas de Praia do Flamengo e Stella Maris. Seu curso segue paralelo à costa, em direção ao município de Lauro de Freitas, desembocando na foz do Rio Joanes.

O curso do Rio Sapato e o ponto de coleta para esse rio, em seu trecho localizado em Salvador são apresentados na Figura 13.

\subsubsection{Bacia Hidrográfica do Lobato}

A Bacia do Lobato se encontra no Subúrbio Ferroviário, uma região carente, com condições precárias de moradia, infraestrutura e saneamento. A Figura 14 mostra o curso desse rio e o ponto de coleta. 
Figura 12: Curso d'água da bacia hidrográfica do rio dos Macacos, Salvador-BA.

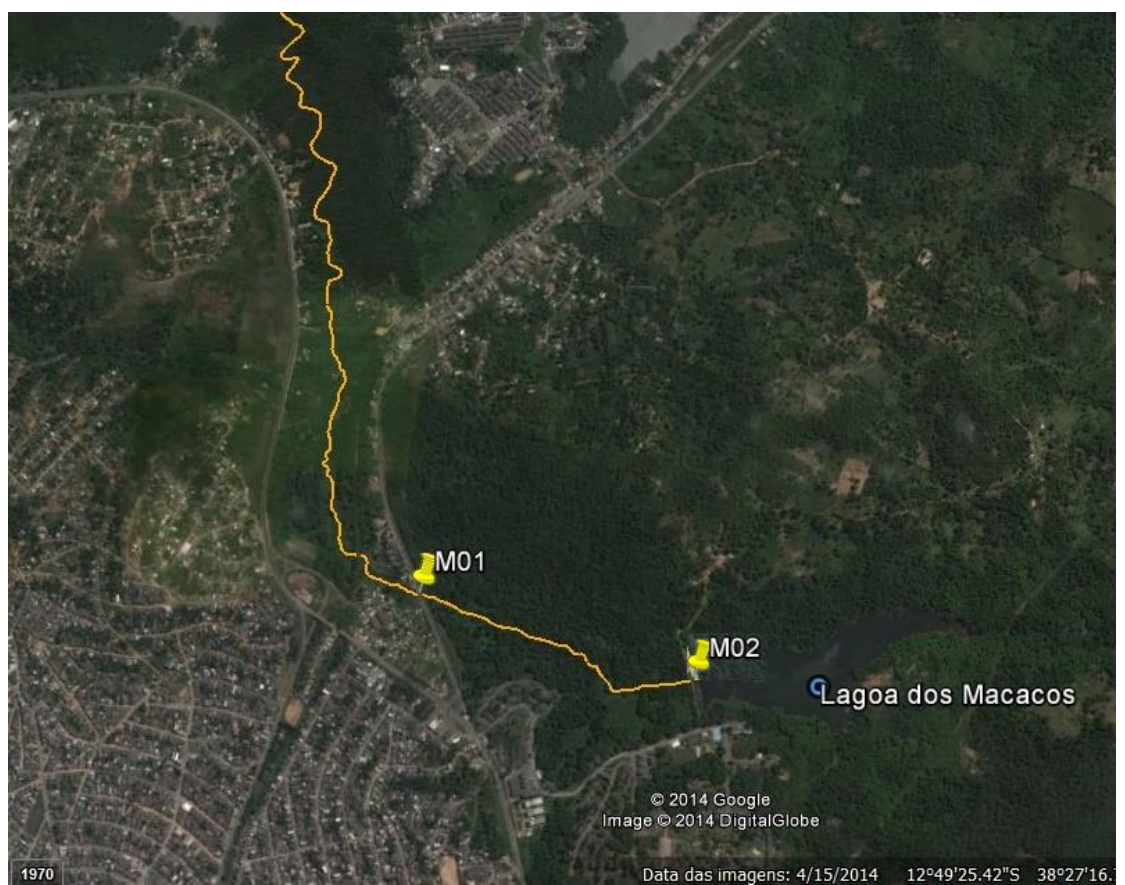

Fonte: INEMA, 2013/2014.

Figura 13: Curso d'água da bacia hidrográfica do rio dos Sapatos, Salvador-BA

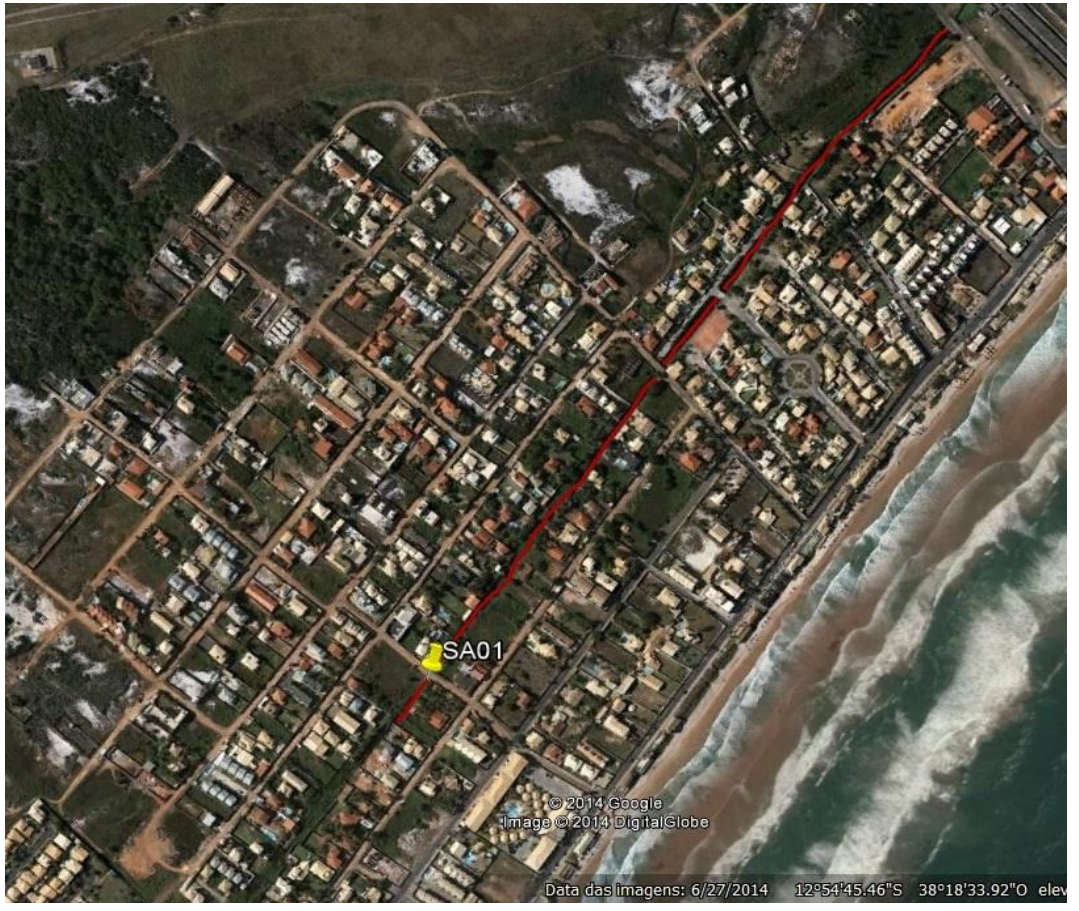

Fonte: INEMA, 2013/2014. 
Figura 14: Curso d'água da bacia hidrográfica do Lobato, Salvador-BA

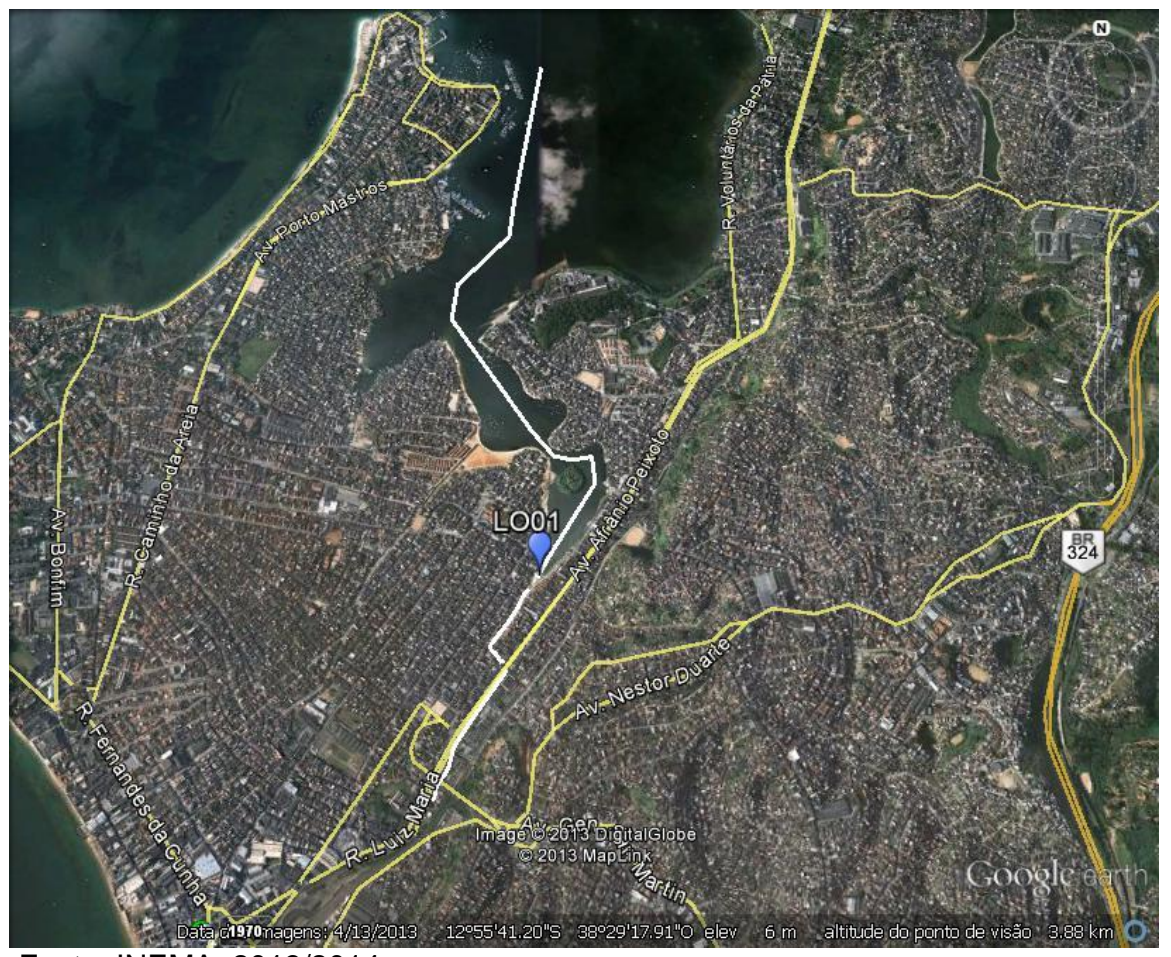

Fonte: INEMA, 2013/2014.

\subsubsection{LAURO DE FREITAS}

As bacias Hidrográficas do município de Lauro de Freitas contempladas são: Bacia Hidrográfica do rio Joanes, sub-bacias do rio Ipitanga e do rio Sapato.

\subsubsection{Bacia Hidrográfica do Rio Joanes}

O rio Joanes nasce no município de São Francisco do Conde (Fazenda Campinas), localizado no recôncavo da Bahia, e desemboca na praia de Buraquinho, no município de Lauro de Freitas. Os municípios que compõem a bacia hidrográfica desse rio são: Lauro de Freitas, Camaçari, Simões Filho, São Sebastião do Passé, São Francisco do Conde, Candeias, Salvador e Dias D'Ávila. Com a área de aproximadamente $755 \mathrm{Km}^{2}$, o rio Joanes limita-se com a bacia do rio Jacuípe, as bacias da área urbana de Salvador, e a sudeste o limite da bacia é definido pelo oceano Atlântico (RIO JOANES, 2009).

O rio Joanes faz parte de uma APA (Área de Preservação Ambiental) e abastece a região metropolitana de Salvador. Essa APA apresenta cobertura vegetal compatível com as áreas de proteção do manancial, embora a bacia venha sofrendo com intensas modificações no uso do solo ao longo dos anos, com a substituição da vegetação nativa por outro tipo de vegetação, e um intenso processo de urbanização. Associado a esses fatores, o rio Joanes teve o seu curso de água barrado.

O curso do Rio Joanes em Lauro de Freitas consta na Figura 15.

\subsubsection{Bacia Hidrográfica do Rio Ipitanga}

O rio Ipitanga é utilizado para abastecimento de água do município de Salvador. Nasce no município de Simões Filho, passa por Salvador e deságua em Lauro de Freitas, no rio Joanes, sendo seu principal afluente. A extensão linear do rio Ipitanga é de $30 \mathrm{~km}$ e sua bacia hidrográfica drena uma área de $118 \mathrm{~km}^{2}$. Os principais afluentes são os rios Poti, Cabuçu, Cururipe, das Margaridas, Itinga, Caji e Ribeirão Itapoá. O uso das águas do rio Ipitanga e seus afluentes são, principalmente, para abastecimento doméstico e industrial, e também para a dessedentação de animais, lazer e esportes náuticos, pesca e como corpo receptor de efluentes líquidos.

O curso do Rio Ipitanga e os pontos de coleta para este rio constam na Figura 16.

\subsubsection{Bacia Hidrográfica do Rio Sapato}

A nascente do rio Sapato está situada no Parque das Dunas de Salvador-Ba, um parque urbano de dunas, restingas e lagoas com área total de $4.950 .000 \mathrm{~m}^{2}$ (lagoa da Vitória). Seu curso segue em uma reta seguindo a costa, em direção ao município de Lauro de Freitas, e desembocando na foz do Rio Joanes. 
A Figura 17 mostra o curso do Rio Sapato em Lauro de Freitas e os pontos de coleta sugeridos para este rio, incluindo Salvador e Lauro de Freitas.

Figura 15: Curso d'água da bacia hidrográfica do Rio Joanes, Lauro de Freitas-BA

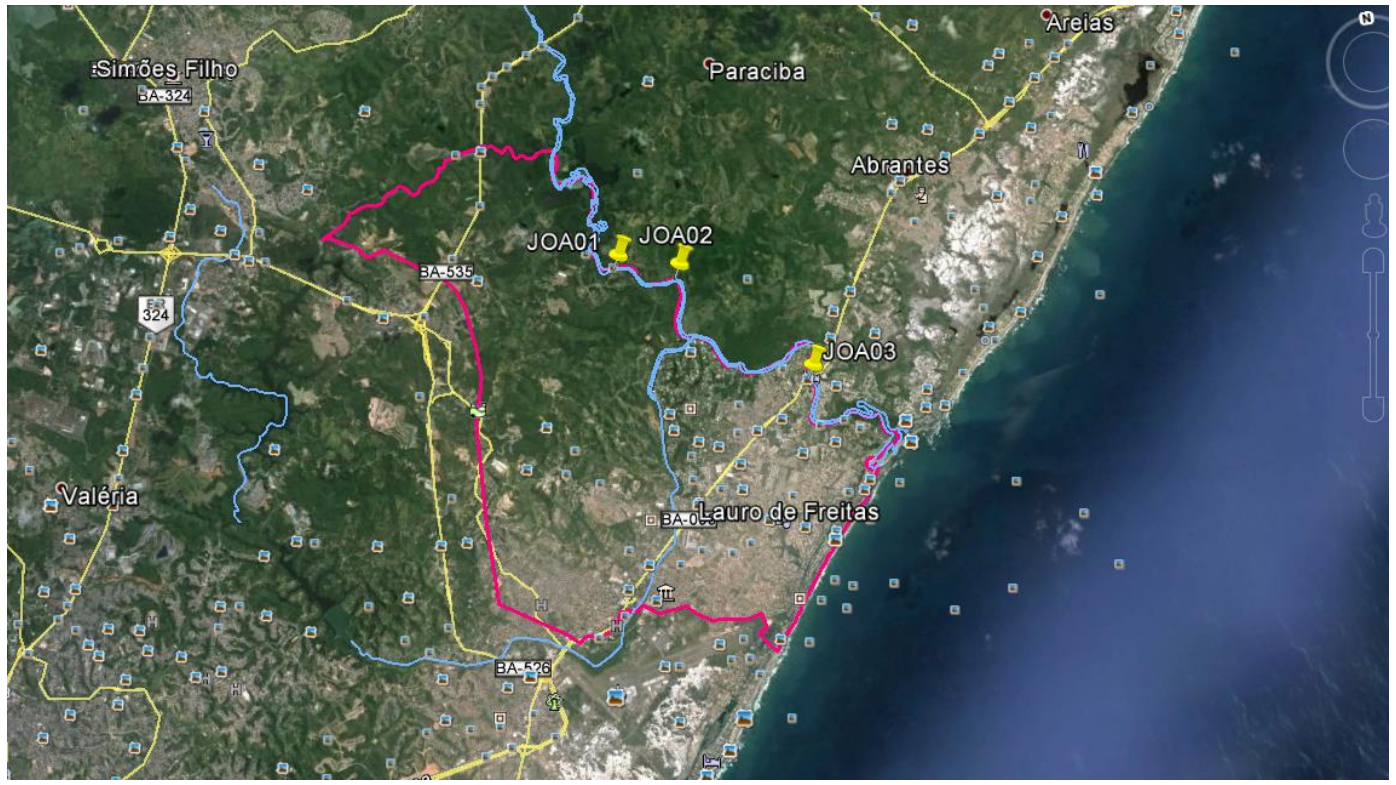

Fonte: INEMA, 2013/2014.

Figura 16: Curso d'água da bacia hidrográfica do Rio Ipitanga, Lauro de Freitas-BA

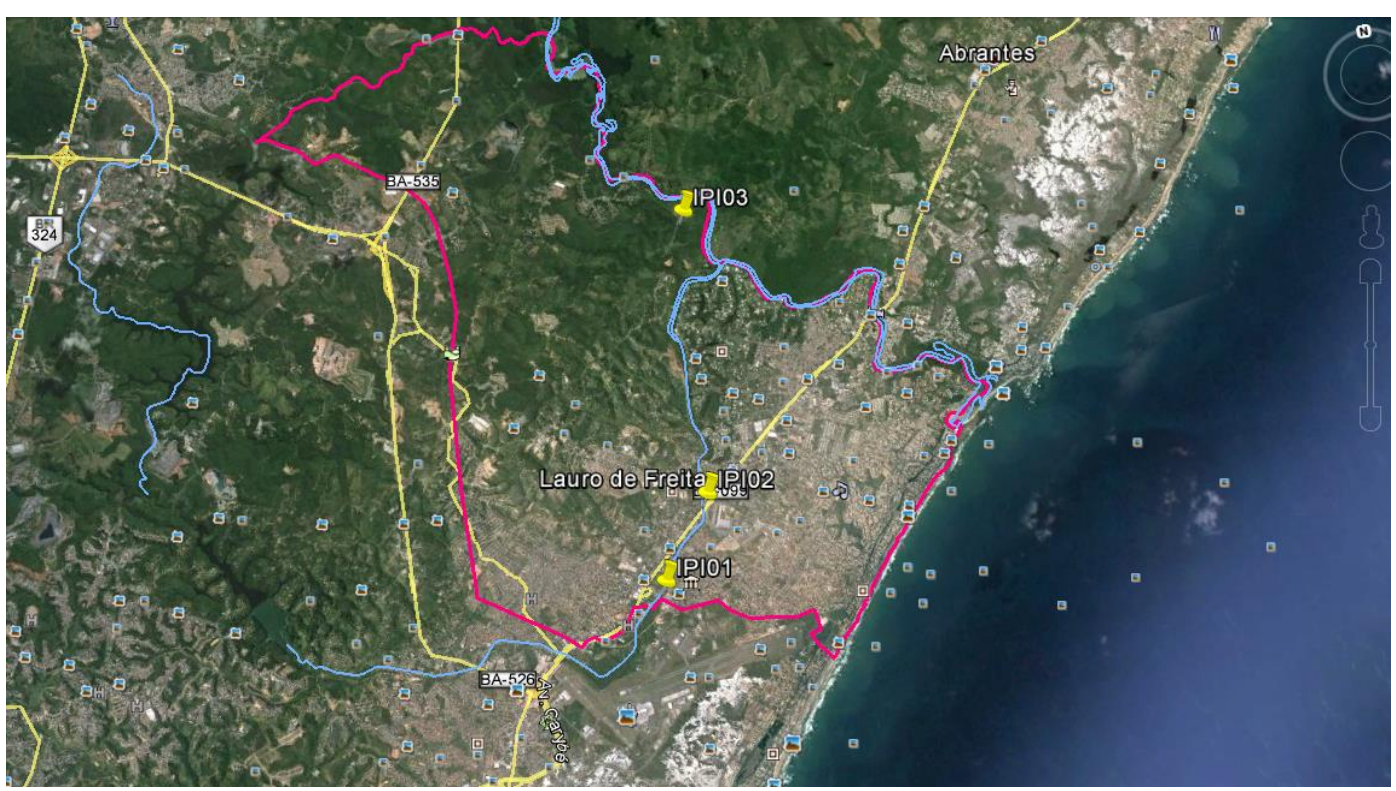

Fonte: INEMA, 2013/2014. 
Figura 17: Curso d'água da bacia hidrográfica do Rio Sapato, Lauro de Freitas-BA

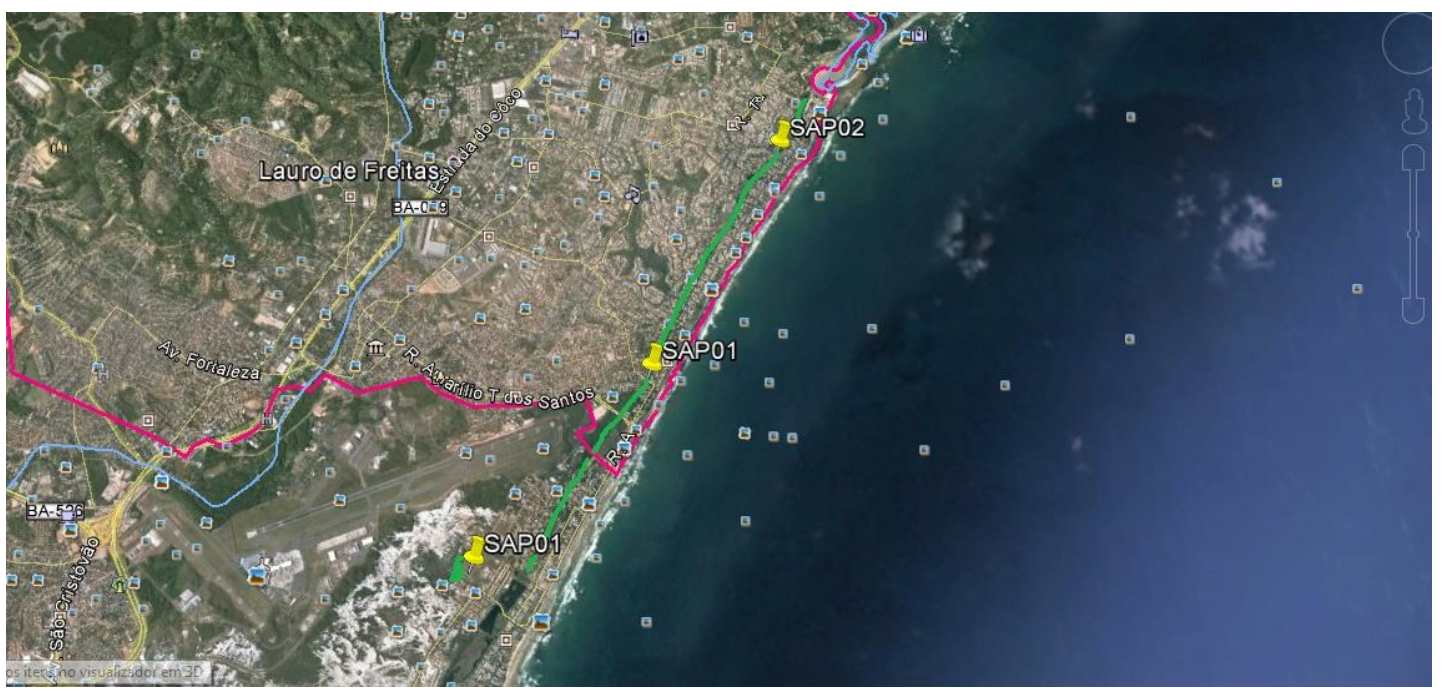

Fonte: INEMA, 2013/2014.

\subsection{COLETA E ANÁLISE}

Este diagnóstico vem sendo realizado ao longo dos anos de 2013 a 2016. Para a última avaliação, as coletas foram realizadas na primeira quinzena de novembro de 2016, no período de 07 a 09, para as referidas bacias urbanas e seus pequenos rios e córregos que cortam a cidade.

\subsubsection{CALCULO DOS ÍNDICES}

Foram avaliados parâmetros específicos para compor os Índices IQA e IET, além de outras variáveis, com o intuito de avaliar a qualidade das águas dos mananciais de Salvador e Lauro de Freitas (Tabela 1).

A escolha dos parâmetros foi baseada nos índices de qualidade ambiental, ou seja, IQA (Índice de Qualidade da Água) e IET (Índice do Estado Trófico).

O IQA (Índice de Qualidade da Água) foi desenvolvido para avaliar a qualidade da água bruta, visando ao seu uso para o abastecimento público, após tratamento. Os parâmetros utilizados no cálculo do IQA são, em sua maioria, indicadores de ações antropogênicas, como, por exemplo, contaminações por esgotos domésticos e efluentes industriais. Por tanto, a escolha dos parâmetros está interligada às características básicas que determinem possibilidade da água apresentar um padrão de qualidade aceitável para o consumo humano e para manutenção dos ecossistemas aquáticos.

O cálculo do IQA é feito por meio do produtório ponderado dos nove parâmetros, segundo a seguinte fórmula (CETESB, 2007):

$$
\mathrm{IQA}=\prod_{\mathrm{i}=1}^{\mathrm{n}} \mathrm{q}_{\mathrm{i}}^{\mathrm{w}}{ }^{\mathrm{i}}
$$

onde:

IQA = Índice de Qualidade das Águas. Um número entre 0 e 100;

qi $=$ qualidade do i-ésimo parâmetro. Um número entre 0 e 100, obtido do respectivo gráfico de qualidade, em função de sua concentração ou medida (resultado da análise);

wi = peso correspondente ao i-ésimo parâmetro fixado em função da sua importância para a conformação global da qualidade, isto é, um número entre 0 e 1 , de forma que:

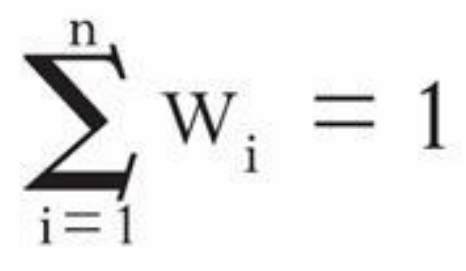

sendo $n$ o número de parâmetros que entram no cálculo do IQA.

As variáveis utilizadas para o cálculo do IQA são a temperatura, $\mathrm{pH}$, oxigênio dissolvido (OD), demanda bioquímica de oxigênio (DBO), coliformes termotolerantes, nitrogênio total, fósforo total, turbidez e sólidos totais. A partir dos valores encontrados pelo cálculo do IQA, é possível classificar a qualidade ambiental das águas (Tabela 2). 
Tabela 1: Variáveis da qualidade ambiental e limites (Resolução CONAMA 357|2005)

\begin{tabular}{|c|c|c|}
\hline Parâmetros & Método & $\begin{array}{c}\text { Limites Resolução CONAMA } \\
357 / 2005 \text {, Classe } 2\end{array}$ \\
\hline Temperatura & SMEWW $2550 \mathrm{~B}$ & - \\
\hline $\mathrm{pH}$ & SMEWW $4500 \mathrm{H}+\mathrm{B}$ & 6,0 a 9,0 \\
\hline Oxigênio Dissolvido & SMEWW 4500 O G & $\geq 5,0 \mathrm{mg} / \mathrm{L} \mathrm{O} 2$ \\
\hline $\begin{array}{lll}\text { Demanda } & \text { Bioquímica de } \\
\text { Oxigênio } & & \\
\end{array}$ & SMEWW 5210 B & $\leq 5 \mathrm{mg} / \mathrm{L} \mathrm{O} 2$ \\
\hline $\begin{array}{l}\text { Coliformes } \\
\text { Termotolerantes }\end{array}$ & SMEWW $9221 \mathrm{C}, \mathrm{E}$ & - \\
\hline Nitrogênio Total & SMEWW $4500 \mathrm{~N} \mathrm{C}$ & - \\
\hline Fósforo Total & SMEWW $4500 \mathrm{P}$ E & $\begin{array}{c}\leq 0,030 \mathrm{mg} / \mathrm{L} \text { (Lêntico) e } \leq 0,050 \\
\mathrm{mg} / \mathrm{L} \text { (Lótico) }\end{array}$ \\
\hline Turbidez & SMEWW $2130 \mathrm{~B}$ & $\leq 100$ UNT \\
\hline Sólidos Totais & SMEWW $2540 \mathrm{~B}$ & - \\
\hline Clorofila a & SMEWW $10200 \mathrm{H}$ & $\leq 30 \mu \mathrm{g} / \mathrm{L}$ \\
\hline Surfactante & SMEWW $5540 \mathrm{C}$ & 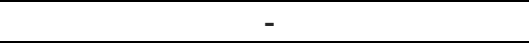 \\
\hline Nitrato & SMEWW $4110 \mathrm{~B}$ & Nitrato $10,0 \mathrm{mg} / \mathrm{L} \mathrm{N}$ \\
\hline Sólidos Dissolvidos Totais & SMEWW $2540 \mathrm{C}$ & $500 \mathrm{mg} / \mathrm{L}$ \\
\hline Condutividade Elétrica & SMEWW $2510 \mathrm{~B}$ & - \\
\hline Salinidade & SMEWW $2520 \mathrm{~B}$ & - \\
\hline $\begin{array}{lll}\text { Saturação } & \text { de } & \text { Oxigênio } \\
\text { Dissolvido } & & \\
\end{array}$ & SMEWW 4500 O G & - \\
\hline Nitrogênio Amoniacal & SMEWW $4500 \mathrm{~F}$ & $\begin{array}{c}3,7 \mathrm{mg} / \mathrm{L} \mathrm{N} \text {, para } \mathrm{pH} £ 7,5 \\
2,0 \mathrm{mg} / \mathrm{L} \mathrm{N} \text {, para } 7,5<\mathrm{pH} £ 8,0 \\
1,0 \mathrm{mg} / \mathrm{L} \mathrm{N}, \text { para } 8,0<\mathrm{pH} £ 8,5 \\
0,5 \mathrm{mg} / \mathrm{L} \mathrm{N} \text {, para } \mathrm{pH}>8,5\end{array}$ \\
\hline
\end{tabular}

Fonte: BRASIL, 2005.

Tabela 2: Classificação da qualidade ambiental das águas

\begin{tabular}{ccccc} 
Ótimo & Bom & Regular & Ruim & Péssimo \\
$79<\mathrm{IQA} \leq 100$ & $51<\mathrm{IQA} \leq 79$ & $36<\mathrm{IQA} \leq 51$ & $19<\mathrm{IQA} \leq 36$ & $\mathrm{IQA} \leq 19$ \\
\hline
\end{tabular}

Fonte: CETESB, 2007.

O Índice do Estado Trófico tem por finalidade classificar corpos d'água em diferentes graus de trofia, ou seja, avalia a qualidade da água quanto ao enriquecimento por nutrientes e seu efeito relacionado ao crescimento excessivo das algas ou ao aumento da infestação de macrófitas aquáticas.

O processo de eutrofização é um dos principais causadores da degradação da qualidade das águas, e se caracteriza tanto por ações naturais quanto antrópicas, como lançamento de efluentes domésticos e industriais no corpo receptor.
Em rios, o cálculo do IET, a partir dos valores de fósforo total, é feito pela seguinte fórmula, segundo Lamparelli (2004):

$\mathrm{IET}=10 \cdot(6-((0,42-0,36 \cdot(\operatorname{In} \cdot \mathrm{PT}) / \mathrm{In} 2))$, onde $\mathrm{o}$ fósforo total (PT) é expresso em $\mu \mathrm{g} / \mathrm{L}$.

As variáveis utilizadas para o cálculo do IET são o fósforo total - relacionado ao potencial de eutrofização -, e a clorofila $a$ - efeito resposta sob o nível de crescimento de algas. A partir dos valores encontrados pelo calculo do IET, é possível classificar o ambiente quanto ao estado trófico (Tabela 3).

Tabela 3: Classificação dos níveis de estado trófico Ultraoligotrófico Oligotrófico Mesotrófico Eutrófico Supereutrófico Hipereutrófico IET $<47$ IET - 47 a 52 IET - 52 a 59 IET - 59 a 63 IET - 63 a 67 IET $>67$

Fonte: Lamparelli, 2004. 


\section{RESULTADOS E DISCUSSÃO}

Os resultados foram interpretados de acordo com a Resolução CONAMA n० 357, de 17 de março de 2005, que estabelece as condições e padrões de qualidade das águas com limites individuais para cada substância em cada classe. Os pontos alocados nas bacias hidrográficas de Salvador e Lauro de Freitas foram definidos como águas doces, Classe 2, e águas salobras, Classe 1 (BRASIL, 2005).

Vale ressaltar que a referida Resolução estabelece nas disposições finais e transitórias que, "enquanto não aprovados os respectivos enquadramentos, as águas doces serão consideradas classe 2 , as salinas e salobras classe 1 , exceto se as condições de qualidade atuais forem melhores, o que determinará a aplicação da classe mais rigorosa correspondente" (BRASIL, 2005, p. 26).

Foram avaliados os parâmetros temperatura, $\mathrm{pH}$, turbidez, condutividade, OD, salinidade, sólidos totais, porcentagem de OD, surfactantes, $\mathrm{DBO}$, fósforo total, nitrogênio amoniacal, nitrogênio total, sólidos totais, nitrogênio nitrato, clorofila a e coliformes termotolerantes (Tabela 1). Durante o período de estudo, o valor máximo de temperatura registrado foi $32,0^{\circ} \mathrm{C}$ e o valor mínimo, $23,9^{\circ} \mathrm{C}$, levando em consideração a estação do ano Primavera.

A variável $\mathrm{pH}$ violou em um trecho da Bacia dos Seixos (S01). A Turbidez foi violada na Bacia Hidrográfica de Ondina (O01), Rio Passa Vaca (PV00), Rio Jaguaribe (J12) e Rio Paraguari (PA01). O Oxigênio Dissolvido foi violado na maioria da malha amostral, exceto na Bacia Hidrográfica do Rio das Pedras (Pituaçu) (P-01, P-02 e P-05), Rio Ipitanga (I-02), Rio dos Macacos (M01) e Bacia do Rio Joanes (JOA01, JOA02 e JOA03). O mesmo aconteceu para o parâmetro DBO que, na maioria da rede de amostragem, foi violado, exceto para a Bacia do Rio dos Seixos (S01 e S02), Rio Lucaia (L03), Rio das Pedras (P05), Rio do Cobre (CO01 e CO02), Rio Ipitanga (I-01 e I02), Rio dos Macacos (M01 e M02), Rio Joanes (JOA01, JOA02 e JOA03) e Rio Sapato (SAP02 e SAP03). Para variável Fósforo total, as Bacias Hidrográficas dos Seixos (S01), Rio Pituaçu (P-05), Rio Passa Vaca (PV03), Rio do Cobre (CO02), Rio Ipitanga (I02), Rio dos Macacos (M01) e Rio Joanes (JOA01) não violaram o padrão estabelecido, o mesmo ocorreu para o parâmetro Nitrogênio Amoniacal, incluindo a Bacia Hidrográfica do Rio Ipitanga (I-02) e Rio do Cobre (CO02). A maioria da malha amostral não violou o parâmetro Nitrogênio Nitrato, exceto o Rio das Pedras (P05), Rio Passa Vaca (PV03) e o Rio dos Macacos (M01). Para a variável Clorofila $a$, houve violação na Bacia Hidrográfica Rio Camarajipe (CA01), Rio Ipitanga (103) e Rio Joanes (JOA01 e JOA03).

Embora a Resolução do CONAMA 357/05 não estabeleça valores-padrão para o parâmetro de condutividade, sólidos dissolvidos, porcentagem de OD, surfactantes, nitrogênio total e sólidos totais, é notória a degradação ambiental nas Bacias Hidrográficas, devido aos altos valores encontrados.

Seguem, abaixo, os dados das variáveis de qualidade da água apresentados nas tabelas 4, 5, 6,7 e 8 .

\section{1 Índice da Qualidade das Águas (IQA) e Índice do Estado Trófico (IET)}

A qualidade ambiental das águas das Bacias Hidrográficas de Salvador e Lauro de Freitas foi classificada de acordo com o IQA e o IET. Com isto, os trechos avaliados apresentam cenários similares (Quadro 2).

Foram avaliados 54 pontos de amostragem nos rios de Salvador e Lauro de Freitas. Quanto ao Índice da Qualidade, $69,8 \%$ dos pontos foram classificados pelo IQA como "Ruim" ou "Péssimo", $20,75 \%$ como "Regular" e apenas $9,43 \%$ como "Bom".

Relacionado à eutrofização, de acordo com cálculo do Índice do Estado Trófico (IET), todos os pontos apresentaram algum nível de eutrofização, mesmo aqueles que apresentaram uma boa qualidade. A maior parte, quase $49,99 \%$, apresentou eutrofização num estado avançado (Supereutrófico e Hipereutrófico), ou seja, 27,77\% dos pontos da malha amostral comportaram-se como Hipereutrófico, que, de acordo com Lamparelli (2004), são corpos d'água afetados significativamente pelas elevadas concentrações de matéria orgânica e nutrientes, com consequências indesejáveis para seus usos múltiplos. Já $22,22 \%$ dos pontos de amostragem apresentaram resultados como Supereutrófico, que a autora classifica como um corpo d'água com alta produtividade em relação às condições naturais, de baixa transparência, em geral afetado por atividades antrópicas, no qual ocorrem, com frequência, alterações indesejáveis na qualidade da água, como a ocorrência de episódios de florações de algas e interferências nos seus múltiplos usos (LAMPARELLI, 2004). 
Os demais pontos foram classificados como "Eutrófico", "Mesotrófico", e pouco menos que 1\% "Ultraoligotrófico", que se trata de corpo d'água limpo.

A malha amostral com 25,92\% foi classificada como Eutrófico, que se trata de corpo d'água com alta produtividade em relação às condições naturais, com redução da transparência, em geral afetados por atividades antrópicas, nos quais ocorrem alterações indesejáveis na qualidade da água decorrentes do aumento da concentração de nutrientes e interferências nos seus múltiplos usos (LAMPARELLI, 2004).

Dos trechos avaliados, 22,22\% foram determinados como Mesotrófico, que são corpos d'água com produtividade intermediária, com possíveis implicações sobre a qualidade da água, mas em níveis aceitáveis, na maioria dos casos.

Quadro 2: Resultado da qualidade ambiental das Bacias Hidrográficas de Salvador e Lauro de Freitas, IQA e IET, 2016

\begin{tabular}{|c|c|c|}
\hline Pontos de Amostragem & IQA & IET \\
\hline \multicolumn{3}{|c|}{ Bacia do Rio dos Seixos } \\
\hline (S-01) & 40,000 & 59,78 \\
\hline (S-02) & 34,000 & 63,99 \\
\hline \multicolumn{3}{|c|}{ Bacia do Rio Ondina } \\
\hline$(001)$ & 17,000 & 59,99 \\
\hline \multicolumn{3}{|c|}{ Bacia do Rio Lucaia } \\
\hline (L-01) & 23,000 & 57,55 \\
\hline (L-02) & 29,000 & 58,02 \\
\hline (L-03) & 32,000 & 63,50 \\
\hline \multicolumn{3}{|c|}{ Bacia do Rio Camarajipe } \\
\hline (Ca01) & 18,000 & 82,47 \\
\hline (Ca02) & 18,000 & 58,60 \\
\hline (Ca03) & 19,000 & 58,94 \\
\hline (Ca04) & 22,000 & 58,72 \\
\hline (Ca07) & 21,000 & 58,02 \\
\hline (Ca08) & 18,000 & 62,41 \\
\hline \multicolumn{3}{|c|}{ Bacia do Rio das Pedras (Pituaçu) } \\
\hline$(\mathrm{P}-01)$ & 25,000 & 60,95 \\
\hline (P-02) & 22,000 & 59,16 \\
\hline (P-07) & 29,000 & 62,01 \\
\hline (P-03) & 22,000 & 63,52 \\
\hline$(\mathrm{P}-04)$ & 19,000 & 59,69 \\
\hline (P-05) & 71,000 & 45,83 \\
\hline$(\mathrm{P}-06)$ & 32,000 & 64,73 \\
\hline (P-07) & 29,000 & 64,89 \\
\hline (P-08) & 30,000 & 62,34 \\
\hline \multicolumn{3}{|c|}{ Bacia do Rio Passa Vaca } \\
\hline (Pv00) & 14,000 & 69,74 \\
\hline (Pv03) & 57,000 & 57,78 \\
\hline \multicolumn{3}{|c|}{ Bacia do Rio Jaguaribe } \\
\hline$(\mathrm{J}-01)$ & 27,000 & 73,89 \\
\hline$(\mathrm{J}-02)$ & 31,000 & 66,89 \\
\hline$(\mathrm{J}-03)$ & 19,000 & 73,43 \\
\hline$(\mathrm{J}-04)$ & 21,000 & 68,31 \\
\hline$(\mathrm{J}-05)$ & 28,000 & 62,80 \\
\hline$(\mathrm{J}-06)$ & 28,000 & 64,65 \\
\hline$(\mathrm{J}-07)$ & 40,000 & 63,36 \\
\hline$(\mathrm{J}-10)$ & 32,000 & 65,40 \\
\hline$(\mathrm{J}-11)$ & 13,000 & 59,19 \\
\hline$(\mathrm{J}-12)$ & 16,000 & 66,84 \\
\hline \multicolumn{3}{|c|}{ Bacia do Rio do Cobre } \\
\hline (Co01) & 35,000 & 61,60 \\
\hline (Co02) & 50,000 & 57,47 \\
\hline
\end{tabular}




\begin{tabular}{|c|c|c|}
\hline \multicolumn{3}{|c|}{ Bacia do Rio Paraguari } \\
\hline (Pa01) & 17,000 & 69,37 \\
\hline (Pa02) & 31,000 & 60,15 \\
\hline (Pa03) & 27,000 & 67,02 \\
\hline \multicolumn{3}{|c|}{ Bacia do Rio Ipitanga } \\
\hline$(1-01)$ & 40,000 & 69,74 \\
\hline$(1-02)$ & 67,000 & 56,03 \\
\hline$(1-03)$ & 28,000 & 79,14 \\
\hline$(\mathrm{I}-04)$ & 27,000 & 71,28 \\
\hline$(1-05)$ & 41,000 & 56,09 \\
\hline \multicolumn{3}{|c|}{ Bacia do Rio dos Macacos } \\
\hline (M-01) & 79,000 & 55,75 \\
\hline$(\mathrm{M}-02)$ & 32,000 & 66,09 \\
\hline \multicolumn{3}{|c|}{ Bacia do Rio Lobato } \\
\hline (LO01) & 17,000 & 66,50 \\
\hline \multicolumn{3}{|c|}{ Bacia do Rio Joanes } \\
\hline (Joa01) & 69,000 & 60,67 \\
\hline (Joa02) & 51,000 & 71,89 \\
\hline (Joa03) & 36,000 & 78,13 \\
\hline \multicolumn{3}{|c|}{ Bacia do Rio Ipitanga } \\
\hline IPI01 & 30,000 & 71,74 \\
\hline IPI02 & 26,000 & 75,80 \\
\hline IPI03 & 27,000 & 75,60 \\
\hline \multicolumn{3}{|c|}{ Bacia do Rio Sapato } \\
\hline (SAP01) & 33,000 & 31,15 \\
\hline (SAP02) & 35,000 & 58,93 \\
\hline (SAP03) & 35,000 & 65,20 \\
\hline
\end{tabular}

Fonte: Próprio Autor, 2017

\section{CONSIDERAÇÕES FINAIS}

É preciso maior divulgação quanto à qualidade ambiental dos rios urbanos de Salvador e Lauro de Freitas, pois a presença dos rios na organização urbana das cidades tem uma grande importância, tanto sob o ponto de vista ambiental e ecológico, como elemento marcante nas paisagens destas cidades. Ou seja, apesar do contexto apresentado, os resultados $(69,8 \%$ dos trechos avaliados foram classificados como Ruim ou Péssimo) mostram que os rios urbanos, em geral, se apresentam degradados, poluídos, tendo seus leitos adulterados pelas retificações, servindo como depósito de lixo e esgoto, e com as populações residentes às suas margens voltando-Ihes as costas. Isto é justificado devido ao processo de urbanização das cidades, como resultado da ação do homem sobre esses elementos naturais.

Neste sentido, é imprescindível promover ações para a restauração, reabilitação e a revitalização dos cursos d'água, em virtude da vertente de valorização dos rios urbanos. 
Tabela 4: Resultados das variáveis de qualidade da água para as Bacias Hidrográficas de Salvador, Bacia do Rio dos Seixos, Bacia do Rio Ondina, Bacia do Rio Lucaia e Bacia do Rio Camarajipe, Bahia

\begin{tabular}{|c|c|c|c|c|c|c|c|c|c|c|c|c|c|c|}
\hline \multirow[t]{2}{*}{ Parâmetros } & \multirow{2}{*}{$\begin{array}{c}\text { Padrões da } \\
\text { Resolução } \\
\text { CONAMA no. } \\
\text { 357/05, águas } \\
\text { doces, classes } 2\end{array}$} & \multirow[t]{2}{*}{ Unidade } & \multicolumn{2}{|c|}{$\begin{array}{l}\text { Bacia do Rio } \\
\text { dos seixos }\end{array}$} & \multirow{2}{*}{$\begin{array}{c}\begin{array}{c}\text { Bacia } \\
\text { do Rio } \\
\text { Ondina }\end{array} \\
(001)\end{array}$} & \multicolumn{3}{|c|}{ Rio Lucaia } & \multicolumn{6}{|c|}{ Bacia do Rio Camarajipe } \\
\hline & & & (S-01) & (S-02) & & (L-01) & $(\mathrm{L}-02)$ & (L-03) & (CA01) & (CA02) & (CA03) & (CA04) & (CA07) & (CA08) \\
\hline $\mathrm{pH}$ & 6,0 a 9,0 & - & 5,96 & 6,36 & 6,45 & 6,48 & 6,48 & 6,77 & 6,86 & 6,90 & 6,86 & 6,96 & 6,70 & 6,73 \\
\hline $\begin{array}{l}\text { \% Saturação de } \\
\text { Oxigênio } \\
\text { Dissolvido }\end{array}$ & - & $\%$ & 43,4 & 38,6 & 22,6 & 30,9 & 28,2 & 31,8 & 26,0 & 33,4 & 27,6 & 30,1 & 35,2 & 16,8 \\
\hline OD & $\geq 5,0$ & $\mathrm{mg} / \mathrm{L}$ & 3,46 & 3,05 & 1,78 & 2,45 & 2,22 & 2,50 & 2,03 & 2,61 & 2,2 & 2,34 & 2,64 & 1,30 \\
\hline Temperatura & - & $\stackrel{\circ}{ } \mathrm{C}$ & 27,5 & 27,8 & 28,0 & 27,6 & 28,2 & 28,2 & 29,0 & 28,8 & 29,8 & 29,1 & 31,1 & 29,2 \\
\hline $\begin{array}{l}\text { Coliformes } \\
\text { termotolerantes }\end{array}$ & - & $\begin{array}{c}\text { NMP/100 } \\
\mathrm{mL}\end{array}$ & $\begin{array}{c}2,8 \times 10 \\
5\end{array}$ & $\begin{array}{c}2,2 X 1 \\
0^{7}\end{array}$ & $9,2 \times 10^{7}$ & $4,9 \times 10^{8}$ & $1,6 \times 10^{7}$ & $2,6 \times 10^{7}$ & $\begin{array}{c}2,4 \times 10 \\
9\end{array}$ & $\begin{array}{c}1,7 X 10 \\
11\end{array}$ & $\begin{array}{c}5,4 \times 10^{1} \\
0\end{array}$ & $7,0 \times 10^{7}$ & $\begin{array}{c}1,6 \times 10^{1} \\
1\end{array}$ & $2,4 \times 10^{8}$ \\
\hline Clorofila a & $\leq 30$ & $\mu \mathrm{g} / \mathrm{L}$ & 2,88 & $<0,40$ & 1,41 & $<0,40$ & $<40$ & 1,79 & 98,8 & $<0,40$ & $<0,40$ & $<0,40$ & $<0,40$ & 1,09 \\
\hline Surfactantes & - & $\mathrm{mg} / \mathrm{L}$ & 0,22 & 1,23 & 3,62 & 2,64 & 1,89 & 1,12 & 4,72 & 4,35 & 4,14 & 3,95 & 3,51 & 3,86 \\
\hline DBO & $\leq 5,0$ & $\mathrm{mg} / \mathrm{L}$ & $<2$ & 5 & 103 & 27 & 13 & $<2$ & 57 & 44 & 32 & 24 & 33 & 34 \\
\hline Turbidez & $\leq 100,0$ & NTU & 2,3 & 9,1 & 150 & 30 & 22 & 6,4 & 69 & 83 & 37 & 44 & 30 & 38 \\
\hline $\begin{array}{l}\text { Nitrogênio } \\
\text { amoniacal }\end{array}$ & $\begin{array}{c}\leq 3,7 \text { para } \mathrm{pH} \leq \\
7,5 \\
\leq 2 \text { para } 7,5<\mathrm{pH} \\
\leq 8,5 \\
\leq 1 \text { para } 8<\mathrm{pH} \leq \\
8,5 \\
\leq 0,5 \text { para } \mathrm{pH}> \\
8,5\end{array}$ & $\begin{array}{l}\mathrm{mg} \mathrm{N}- \\
\mathrm{NH}_{3} / \mathrm{L}\end{array}$ & 1,4 & 5,7 & 26,7 & 10,8 & 12,4 & 11,2 & 18,4 & 16,0 & 25,1 & 25,2 & 14,5 & 14,6 \\
\hline Nitrogênio total & - & $\mathrm{mg} \mathrm{N} / \mathrm{L}$ & 17 & 18 & 36 & 24 & 24 & 26 & 22 & 22 & 26 & 25 & 20 & 18 \\
\hline Sólidos totais & - & $\mathrm{mg} / \mathrm{L}$ & 256 & 274 & 682 & 379 & 326 & 252 & 474 & 486 & 396 & 404 & 438 & 398 \\
\hline $\begin{array}{l}\text { Sólidos } \\
\text { dissolvidos }\end{array}$ & $\leq 500$ & $\mathrm{mg} / \mathrm{L}$ & 220 & 232 & 404 & 327 & 262 & 228 & 420 & 372 & 370 & 394 & 412 & 360 \\
\hline
\end{tabular}




\begin{tabular}{|c|c|c|c|c|c|c|c|c|c|c|c|c|c|c|}
\hline totais & & & & & & & & & & & & & & \\
\hline $\begin{array}{l}\text { Condutividade a } \\
25^{\circ} \mathrm{C}\end{array}$ & - & $\begin{array}{c}\mu \mathrm{mhos} / \mathrm{c} \\
\mathrm{m}\end{array}$ & 451 & 432 & 762 & 598 & 546 & 480 & 760 & 689 & 725 & 743 & 731 & 623 \\
\hline Salinidade & - & $\%$ & 0,2 & 0,2 & 0,4 & 0,3 & 0,3 & 0,2 & 0,4 & 0,4 & 0,4 & 0,4 & 0,4 & 0,3 \\
\hline $\begin{array}{l}\text { Nitrogênio } \\
\text { Nitrato }\end{array}$ & $\leq 10$ & $\begin{array}{l}\mathrm{mg} \mathrm{N}- \\
\mathrm{NO}_{3} / \mathrm{L}\end{array}$ & 4,50 & 1,04 & 0,03 & $<0,02$ & $<0,02$ & 1,28 & $<0,02$ & $<0,02$ & $<0,02$ & $<0,02$ & $<0,02$ & $<0,02$ \\
\hline Fósforo Total & $\begin{array}{c}\leq 0,03 \text { (Lêntico) } \\
\leq 0,1 \text { (Lótico) }\end{array}$ & $\mathrm{mg} \mathrm{P/L}$ & 0,16 & 0,81 & 0,57 & 1,82 & 2,18 & 1,48 & 2,76 & 2,73 & 3,11 & 2,86 & 2,18 & 2,23 \\
\hline
\end{tabular}

Nota: Os valores em vermelho apresentados na tabela acima se referem às violações aos padrões da Resolução CONAMA $n^{\circ}$. 357/05, águas doces Classe 2

Tabela 5: Resultados das variáveis de qualidade da água para as Bacias Hidrográficas de Salvador, Bacia do Rio Jaguaribe e Bacia do Rio do Cobre, Bahia

\begin{tabular}{|c|c|c|c|c|c|c|c|c|c|c|c|c|c|c|c|}
\hline \multirow[t]{2}{*}{ Parâmetros } & \multirow{2}{*}{$\begin{array}{c}\text { Padrões da } \\
\text { Resolução } \\
\text { CONAMA no. } \\
\text { 357/05, águas } \\
\text { doces, classes } 2 \\
\end{array}$} & \multirow{2}{*}{$\begin{array}{c}\text { Unida } \\
\text { de }\end{array}$} & \multicolumn{10}{|c|}{ Bacia do Rio Jaguaribe } & \multicolumn{3}{|c|}{ Bacia do Rio do Cobre } \\
\hline & & & $(\mathrm{J}-01)$ & $(\mathrm{J}-02)$ & $(\mathrm{J}-03)$ & $(\mathrm{J}-04)$ & $(\mathrm{J}-05)$ & $(\mathrm{J}-06)$ & $(\mathrm{J}-07)$ & $(\mathrm{J}-10)$ & (J11) & (J12) & (CO01) & (CO02) & $\begin{array}{c}(\mathrm{COO3} \\
)\end{array}$ \\
\hline $\mathrm{pH}$ & 6,0 a 9,0 & - & 6,63 & 7,12 & 6,59 & 6,86 & 7,04 & 7,18 & 7,22 & 6,79 & 6,59 & 6,73 & 6,71 & 6,92 & \\
\hline $\begin{array}{l}\text { \% Saturação } \\
\text { de Oxigênio } \\
\text { Dissolvido }\end{array}$ & - & $\%$ & 18,6 & 31,9 & 17,5 & 23,8 & 24,8 & 21,3 & 50 & 32,7 & 22,5 & 23,4 & 55,5 & 25,0 & \\
\hline OD & $\geq 5,0$ & $\mathrm{mg} / \mathrm{L}$ & 1,52 & 2,55 & 1,41 & 1,85 & 1,98 & 1,72 & 3,82 & 2,49 & 1,72 & 1,81 & 4,44 & 1,85 & \\
\hline Temperatura & - & $\stackrel{\circ}{\circ} \mathrm{C}$ & 26,2 & 27,2 & 26,8 & 28,9 & 27,3 & 26,7 & 29,8 & 30,1 & 30,0 & 29,2 & 27,3 & 31,6 & \\
\hline $\begin{array}{l}\text { Coliformes } \\
\text { termotolerant } \\
\text { es }\end{array}$ & - & $\begin{array}{l}\mathrm{NMP} / 1 \\
00 \mathrm{~mL}\end{array}$ & $\begin{array}{c}2,6 \times 1 \\
0^{8}\end{array}$ & $\underset{4}{2,3 \times 10}$ & $\underset{9}{3,3 \times 10}$ & $3,3 \times 10^{9}$ & $\underset{5}{9,2 X 10}$ & $\underset{6}{9,2 X 10}$ & $\underset{5}{5,4 X 10}$ & $\underset{6}{1,1 \times 10}$ & $\underset{5}{3,3 \times 10}$ & $\underset{7}{3,3 \times 10}$ & $3,8 \times 10^{9}$ & $\underset{3}{1,4 \times 10}$ & \\
\hline Clorofila a & $\leq 30$ & $\mu \mathrm{g} / \mathrm{L}$ & 16,2 & 3,97 & 9,60 & 3,31 & 1,09 & 2,22 & 4,35 & 4,68 & $<0,40$ & 3,54 & 1,09 & 2,56 & \\
\hline Surfactantes & - & $\mathrm{mg} / \mathrm{L}$ & 2,30 & 1,14 & 2,97 & 3,45 & 2,69 & 1,20 & 0,68 & 1,57 & 4,56 & 2,10 & 1,42 & $<0,20$ & \\
\hline
\end{tabular}




\begin{tabular}{|c|c|c|c|c|c|c|c|c|c|c|c|c|c|c|}
\hline DBO & $\leq 5,0$ & $\mathrm{mg} / \mathrm{L}$ & 6 & 6 & 20 & 25 & 13 & 11 & 6 & 6 & 31 & 52 & 5 & 2 \\
\hline Turbidez & $\leq 100,0$ & NTU & 20 & 97 & 79 & 25 & 11 & 38 & 20 & 75 & 50 & 170 & 13 & 18 \\
\hline $\begin{array}{l}\text { Nitrogênio } \\
\text { amoniacal }\end{array}$ & $\begin{array}{c}\leq 3,7 \text { para } \mathrm{pH} \leq 7,5 \\
\leq 2 \text { para } 7,5<\mathrm{pH} \leq \\
8,5 \\
\leq 1 \text { para } 8<\mathrm{pH} \leq \\
8,5 \\
\leq 0,5 \text { para } \mathrm{pH}>8,5\end{array}$ & $\begin{array}{l}\mathrm{mg} \mathrm{N-} \\
\mathrm{NH}_{3} / \mathrm{L}\end{array}$ & 20,8 & 18,2 & 24,0 & 26,9 & 21,9 & 19,5 & 21,4 & 18,4 & 29,2 & 27,6 & 13,2 & $<0,4$ \\
\hline $\begin{array}{l}\text { Nitrogênio } \\
\text { total }\end{array}$ & - & $\begin{array}{l}\mathrm{mg} \\
\mathrm{N} / \mathrm{L}\end{array}$ & 22 & 18 & 24 & 30 & 22 & 20 & 22 & 20 & 73 & 30 & 14 & 1 \\
\hline Sólidos totais & - & $\mathrm{mg} / \mathrm{L}$ & 314 & 370 & 382 & 356 & 324 & 306 & 338 & 370 & 434 & 734 & 320 & 201 \\
\hline $\begin{array}{l}\text { Sólidos } \\
\text { dissolvidos } \\
\text { totais }\end{array}$ & $\leq 500$ & $\mathrm{mg} / \mathrm{L}$ & 310 & 320 & 316 & 348 & 306 & 284 & 332 & 318 & 392 & 344 & 300 & 200 \\
\hline $\begin{array}{l}\text { Condutividad } \\
\text { e a } 25^{\circ} \mathrm{C}\end{array}$ & - & $\begin{array}{c}\mu \mathrm{mhos} \\
/ \mathrm{cm}\end{array}$ & 664 & 609 & 657 & 733 & 678 & 635 & 702 & 665 & 797 & 757 & 609 & 313 \\
\hline Salinidade & - & $\%$ & 0,3 & 0,3 & 0,3 & 0,4 & 0,3 & 0,3 & 0,4 & 0,3 & 0,4 & 0,4 & 0,3 & 0,2 \\
\hline $\begin{array}{l}\text { Nitrogênio } \\
\text { Nitrato }\end{array}$ & $\leq 10$ & $\begin{array}{l}\mathrm{mg} \mathrm{N-} \\
\mathrm{NO}_{3} / \mathrm{L}\end{array}$ & $<0,02$ & 0,19 & $<0,02$ & $<0,02$ & $<0,02$ & $<0,02$ & $<0,02$ & 0,66 & 0,05 & $<0,02$ & 0,08 & 0,39 \\
\hline Fósforo Total & $\begin{array}{l}\leq 0,03 \text { (Lêntico) } \\
\leq 0,1 \text { (Lótico) }\end{array}$ & $\mathrm{mg} \mathrm{P} / \mathrm{L}$ & 2,06 & 1,45 & 4,13 & 3,39 & 2,59 & 1,61 & 0,32 & 0,62 & 3,43 & 1,72 & 1,63 & 0,08 \\
\hline
\end{tabular}

Nota: Os valores em vermelho apresentados na tabela acima se referem às violações aos padrões da Resolução CONAMA $n^{\circ}$. 357/05, águas doces Classe 2

Tabela 6: Resultados das variáveis de qualidade da água para as Bacias Hidrográficas de Salvador, Bacia do Rio das Pedras (Pituaçu) e Bacia do Rio Passa Vaca, Bahia

\begin{tabular}{|c|c|c|c|c|c|c|c|c|c|c|c|c|}
\hline \multirow{3}{*}{ Parâmetros } & \multirow{3}{*}{$\begin{array}{c}\text { Padrões da } \\
\text { Resolução CONAMA } \\
\text { no. 357/05, águas } \\
\text { doces, classes } 2\end{array}$} & & \multirow{2}{*}{\multicolumn{8}{|c|}{ Bacia do Rio das Pedras (Pituaçu) }} & \multirow{2}{*}{\multicolumn{2}{|c|}{$\begin{array}{l}\text { Bacia do Rio } \\
\text { Passa Vaca }\end{array}$}} \\
\hline & & \multirow[t]{2}{*}{$\begin{array}{l}\text { Unidad } \\
\mathbf{e}\end{array}$} & & & & & & & & & & \\
\hline & & & $(\mathrm{P}-01)$ & $(\mathrm{P}-02)$ & $(\mathrm{P}-03)$ & $(\mathrm{P}-04)$ & $(\mathrm{P}-05)$ & $(\mathrm{P}-06)$ & (P-07) & (P-08) & (PV00) & (PV03) \\
\hline pH & 6,0 a 9,0 & - & 6,50 & 7,00 & 6,99 & 7,28 & 7,45 & 6,75 & 6,59 & 6,77 & 6,86 & 6,80 \\
\hline \% Saturação & - & $\%$ & 74,2 & 76,7 & 21,9 & 29,1 & 69,9 & 34,7 & 27,1 & 33,1 & 15,1 & 40,8 \\
\hline
\end{tabular}




\begin{tabular}{|c|c|c|c|c|c|c|c|c|c|c|c|c|}
\hline $\begin{array}{l}\text { de Oxigênio } \\
\text { Dissolvido }\end{array}$ & & & & & & & & & & & & \\
\hline OD & $\geq 5,0$ & $\mathrm{mg} / \mathrm{L}$ & 5,80 & 6,14 & 1,75 & 2,29 & 5,94 & 2,80 & 2,20 & 2,63 & 1,18 & 3,39 \\
\hline Temperatura & - & $\stackrel{\circ}{ } \mathrm{C}$ & 28,6 & 27,4 & 27,3 & 28,3 & 23,9 & 26,8 & 26,3 & 27,6 & 28,6 & 25,2 \\
\hline $\begin{array}{l}\text { Coliformes } \\
\text { termotolerant } \\
\text { es }\end{array}$ & - & $\begin{array}{l}\text { NMP/1 } \\
00 \mathrm{~mL}\end{array}$ & $9,2 \times 10^{7}$ & $2,4 \times 10^{6}$ & $4,0 \times 10^{9}$ & $7,9 \times 10^{7}$ & $7,9 \times 10^{2}$ & $7,9 \times 10^{7}$ & $2,4 \times 10^{9}$ & $3,3 \times 10^{9}$ & $\begin{array}{c}9,4 \mathrm{X} 10 \\
8\end{array}$ & $\begin{array}{c}3,3 \times 10 \\
2\end{array}$ \\
\hline Clorofila a & $\leq 30$ & $\mu \mathrm{g} / \mathrm{L}$ & 1,08 & $<0,40$ & 1,13 & $<0,40$ & $<0,40$ & 2,61 & 2,22 & 1,14 & 3,15 & 1,46 \\
\hline Surfactantes & - & $\mathrm{mg} / \mathrm{L}$ & 3,19 & 3,35 & 2,70 & 2,73 & $<0,20$ & 1,86 & 2,37 & 2,71 & 3,50 & $<0,20$ \\
\hline DBO & $\leq 5,0$ & $\mathrm{mg} / \mathrm{L}$ & 35 & 34 & 17 & 34 & $<2$ & 9 & 9 & 15 & 113 & 6 \\
\hline Turbidez & $\leq 100,0$ & NTU & 44 & 82 & 36 & 40 & 3,0 & 23 & 22 & 26 & 160 & 6,0 \\
\hline $\begin{array}{l}\text { Nitrogênio } \\
\text { amoniacal }\end{array}$ & $\begin{array}{c}\leq 3,7 \text { para } \mathrm{pH} \leq 7,5 \\
\leq 2 \text { para } 7,5<\mathrm{pH} \leq 8,5 \\
\leq 1 \text { para } 8<\mathrm{pH} \leq 8,5 \\
\leq 0,5 \text { para } \mathrm{pH}>8,5\end{array}$ & $\begin{array}{l}\mathrm{mg} \mathrm{N-} \\
\mathrm{NH}_{3} / \mathrm{L}\end{array}$ & 20,7 & 30,5 & 30,2 & 33,6 & $<0,4$ & 12,5 & 20,3 & 19,7 & 34,8 & 10,5 \\
\hline $\begin{array}{l}\text { Nitrogênio } \\
\text { total }\end{array}$ & - & $\mathrm{mg} \mathrm{N} / \mathrm{L}$ & 26 & 34 & 35 & 40 & 1 & 12 & 20 & 20 & 40 & 30 \\
\hline Sólidos totais & - & $\mathrm{mg} / \mathrm{L}$ & 416 & 554 & 364 & 420 & 140 & 300 & 302 & 334 & 548 & 248 \\
\hline $\begin{array}{l}\text { Sólidos } \\
\text { dissolvidos } \\
\text { totais }\end{array}$ & $\leq 500$ & $\mathrm{mg} / \mathrm{L}$ & 414 & 382 & 324 & 362 & 134 & 283 & 294 & 324 & 394 & 235 \\
\hline $\begin{array}{l}\text { Condutividad } \\
\text { e a } 25 \circ C\end{array}$ & - & $\begin{array}{c}\mu \mathrm{mhos} / \\
\mathrm{cm}\end{array}$ & 705 & 786 & 743 & 794 & 239,4 & 526 & 610 & 605 & 866 & 517 \\
\hline Salinidade & - & $\%$ & 0,4 & 0,4 & 0,4 & 0,4 & 0,1 & 0,3 & 0,3 & 0,3 & 0,4 & 0,3 \\
\hline $\begin{array}{l}\text { Nitrogênio } \\
\text { Nitrato }\end{array}$ & $\leq 10$ & $\begin{array}{l}\mathrm{mg} \mathrm{N}- \\
\mathrm{NO}_{3} / \mathrm{L}\end{array}$ & $<0,02$ & $<0,02$ & $<0,02$ & $<0,02$ & 0,46 & $<0,02$ & $<0,02$ & $<0,02$ & $<0,02$ & 0,63 \\
\hline Fósforo Total & $\begin{array}{c}\leq 0,03 \text { (Lêntico) } \\
\leq 0,1 \text { (Lótico) }\end{array}$ & $\mathrm{mg} \mathrm{P/L}$ & 1,29 & 3,38 & 3,21 & 4,16 & 0,02 & 1,27 & 1,77 & 2,01 & 6,38 & 0,23 \\
\hline
\end{tabular}

Nota: Os valores em vermelho apresentados na tabela acima se referem às violações aos padrões da Resolução CONAMA nº. 357/05, águas doces Classe 2. 
Tabela 7: Resultados das variáveis de qualidade da água para as Bacias Hidrográficas de Salvador, Bacia do Rio Paraguari, Bacia do Rio Ipitanga, Bacia do Rio dos Macacos e Bacia do Rio Lobato. Bahia

\begin{tabular}{|c|c|c|c|c|c|c|c|c|c|c|c|c|c|c|}
\hline \multirow[t]{2}{*}{ Parâmetros } & \multirow{2}{*}{$\begin{array}{c}\text { Padrões da } \\
\text { Resolução } \\
\text { CONAMA no. } \\
\text { 357/05, águas } \\
\text { doces, classes } 2\end{array}$} & \multirow{2}{*}{$\begin{array}{c}\text { Águas } \\
\text { salobra } \\
\mathrm{s}, \\
\text { classe } \\
1\end{array}$} & \multirow[t]{2}{*}{$\begin{array}{c}\text { Unidad } \\
\mathrm{e}\end{array}$} & \multicolumn{3}{|c|}{ Bacia do Rio Paraguari } & \multicolumn{5}{|c|}{ Bacia do Rio Ipitanga } & \multicolumn{2}{|c|}{$\begin{array}{l}\text { Bacia do Rio dos } \\
\text { Macacos }\end{array}$} & \multirow{2}{*}{ 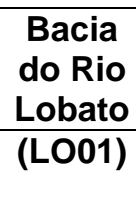 } \\
\hline & & & & (PA01) & (PA02) & (PA03) & $(\mathrm{I}-01)$ & $(\mathrm{I}-02)$ & $(1-03)$ & $(\mathrm{I}-04)$ & $(1-05)$ & (M-01) & (M-02) & \\
\hline $\mathrm{pH}$ & 6,0 a 9,0 & $\begin{array}{c}6,5 \mathrm{a} \\
8,5\end{array}$ & - & 7,04 & 6,70 & 6,96 & 6,38 & 6,32 & 7,11 & 6,96 & 6,88 & 7,02 & 6,90 & 6,86 \\
\hline $\begin{array}{l}\text { \% Saturação } \\
\text { de Oxigênio } \\
\text { Dissolvido }\end{array}$ & - & & $\%$ & 48,2 & 33,0 & 35,6 & 52,2 & 74,7 & 21,3 & 17,1 & 21,3 & 74,8 & 22,0 & 23,8 \\
\hline OD & $\geq 5,0$ & $\geq 5,0$ & $\mathrm{mg} / \mathrm{L}$ & 3,97 & 2,59 & 2,62 & 4,35 & 6,08 & 1,71 & 1,34 & 1,69 & 5,77 & 1,76 & 1,81 \\
\hline Temperatura & - & & ${ }^{\circ} \mathrm{C}$ & 25,8 & 28,4 & 32,0 & 25,0 & 26,5 & 27,1 & 28,4 & 27,6 & 29,3 & 27,2 & 30,1 \\
\hline $\begin{array}{l}\text { Coliformes } \\
\text { termotolerante } \\
\text { s }\end{array}$ & - & & $\begin{array}{c}\mathrm{NMP} / 10 \\
\mathrm{OmL}\end{array}$ & $\underset{8}{9,4 \times 10}$ & $7,0 \times 10^{5}$ & $2,8 \times 10^{6}$ & $1,7 \times 10^{4}$ & $4,9 \times 10^{2}$ & $1,3 \times 10^{6}$ & $\underset{0}{5,4 \times 10^{1}}$ & $3,3 \times 10^{7}$ & $4,5 \times 10$ & $2,2 \times 10^{4}$ & $9,2 \times 10^{7}$ \\
\hline Clorofila a & $\leq 30$ & & $\mu \mathrm{g} / \mathrm{L}$ & 2,61 & 0,76 & 3,64 & 12,9 & 3,31 & 52,8 & 9,64 & $<0,40$ & 2,28 & 2,98 & 2,50 \\
\hline Surfactantes & - & & $\mathrm{mg} / \mathrm{L}$ & 14,1 & 1,69 & 2,44 & 0,22 & $<0,20$ & 2,14 & 2,41 & 2,01 & $<0,20$ & 1,65 & 4,80 \\
\hline DBO & $\leq 5,0$ & & $\mathrm{mg} / \mathrm{L}$ & 229 & 10 & 16 & $<2$ & $<2$ & 6 & 13 & 9 & $<2$ & 5 & 35 \\
\hline Turbidez & $\leq 100,0$ & & NTU & 380 & 11 & 20 & 69 & 38 & 29 & 27 & 19 & 3,7 & 9,7 & 72 \\
\hline $\begin{array}{l}\text { Nitrogênio } \\
\text { amoniacal }\end{array}$ & $\begin{array}{c}\leq 3,7 \text { para } \mathrm{pH} \leq \\
7,5 \\
\leq 2 \text { para } 7,5<\mathrm{pH} \\
\leq 8,5 \\
\leq 1 \text { para } 8<\mathrm{pH} \leq \\
8,5 \\
\leq 0,5 \text { para } \mathrm{pH}> \\
8,5\end{array}$ & $\leq 0,4$ & $\begin{array}{l}\mathrm{mg} \mathrm{N}- \\
\mathrm{NH}_{3} / \mathrm{L}\end{array}$ & 37,0 & 16,9 & 17,2 & 6,2 & $<0,4$ & 20,7 & 16,2 & 10,7 & 1,0 & 18,6 & 21,7 \\
\hline $\begin{array}{l}\text { Nitrogênio } \\
\text { total }\end{array}$ & - & & $\mathrm{mg} \mathrm{N} / \mathrm{L}$ & 48 & 18 & 18 & 7 & 1 & 20 & 24 & 12 & 2 & 18 & 24 \\
\hline Sólidos totais & - & & $\mathrm{mg} / \mathrm{L}$ & 930 & 330 & 3,56 & 222 & 150 & 324 & 328 & 296 & 114 & 304 & 458 \\
\hline
\end{tabular}




\begin{tabular}{|c|c|c|c|c|c|c|c|c|c|c|c|c|c|c|}
\hline $\begin{array}{l}\text { Sólidos } \\
\text { dissolvidos } \\
\text { totais }\end{array}$ & $\leq 500$ & & $\mathrm{mg} / \mathrm{L}$ & 698 & 278 & 342 & 188 & 118 & 282 & 326 & 276 & 110 & 296 & 421 \\
\hline $\begin{array}{l}\text { Condutividade } \\
\text { a } 25 \div C\end{array}$ & - & & $\begin{array}{c}\mu \mathrm{mhos} / \mathrm{c} \\
\mathrm{m}\end{array}$ & 1202 & 653 & 6,96 & 336 & 242,3 & 612 & 596 & 520 & 202,4 & 670 & 795 \\
\hline Salinidade & - & & $\%$ & 0,6 & 0,3 & 0,4 & 0,2 & 0,1 & 0,3 & 0,3 & 0,3 & 0,1 & 0,3 & 0,4 \\
\hline $\begin{array}{l}\text { Nitrogênio } \\
\text { Nitrato }\end{array}$ & $\leq 10$ & $\leq 0,4$ & $\begin{array}{l}\mathrm{mg} \mathrm{N-} \\
\mathrm{NO}_{3} / \mathrm{L}\end{array}$ & $<0,02$ & $<0,02$ & $<0,02$ & $<0,02$ & 0,05 & $<0,02$ & $<0,02$ & $<0,02$ & 0,44 & $<0,02$ & $<0,02$ \\
\hline Fósforo Total & $\begin{array}{c}\leq 0,03 \text { (Lêntico) } \\
\leq 0,1 \text { (Lótico) }\end{array}$ & $\leq 0,124$ & $\mathrm{mg} \mathrm{P} / \mathrm{L}$ & 7,58 & 1,70 & 1,76 & 0,68 & 0,03 & 2,17 & 1,79 & 1,04 & 0,05 & 1,72 & 2,70 \\
\hline
\end{tabular}

Nota: Os valores em vermelho apresentados na tabela acima se referem às violações aos padrões da Resolução CONAMA n. $357 / 05$, águas doces Classe 2.

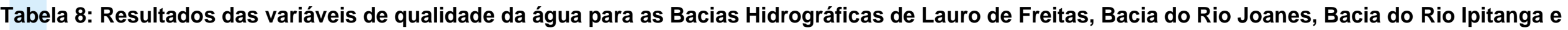
Bacia do Rio Sapato, Bahia

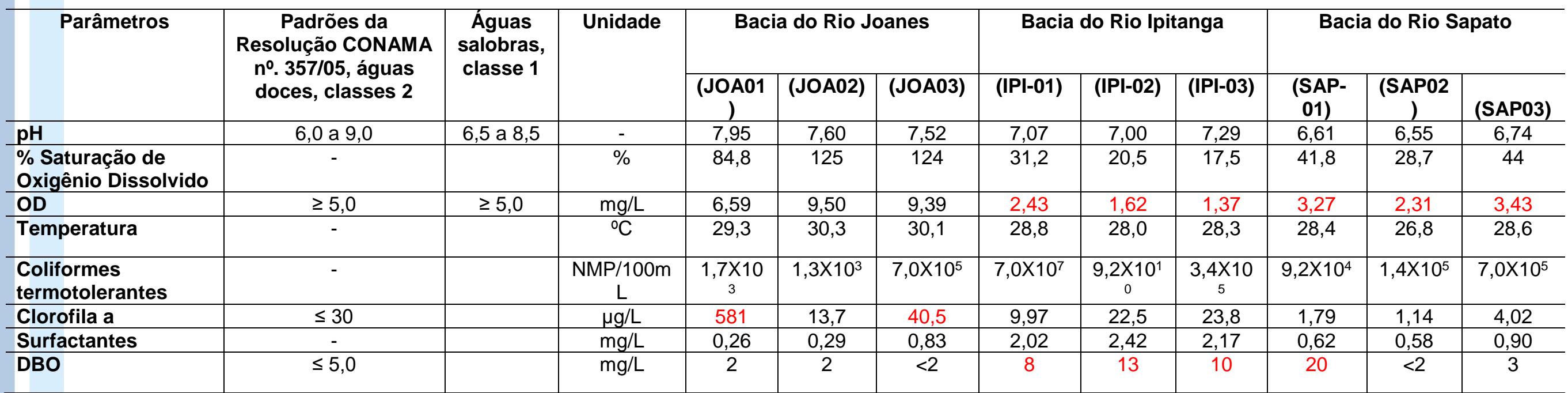




\begin{tabular}{|c|c|c|c|c|c|c|c|c|c|c|c|c|}
\hline Turbidez & $\leq 100,0$ & & NTU & 6,1 & 11 & 26 & 34 & 50 & 29 & 5,5 & 5,7 & 28 \\
\hline $\begin{array}{l}\text { Nitrogênio } \\
\text { amoniacal }\end{array}$ & $\begin{array}{c}\leq 3,7 \text { para } \mathrm{pH} \leq 7,5 \\
\leq 2 \text { para } 7,5<\mathrm{pH} \leq \\
8,5 \\
\leq 1 \text { para } 8<\mathrm{pH} \leq 8,5 \\
\leq 0,5 \text { para } \mathrm{pH}>8,5\end{array}$ & $\leq 0,4$ & $\begin{array}{l}\mathrm{mg} \mathrm{N-} \\
\mathrm{NH}_{3} / \mathrm{L}\end{array}$ & $<0,4$ & 12,2 & 12,7 & 18,6 & 19,1 & 18,5 & 2,1 & 2,2 & 7,6 \\
\hline Nitrogênio total & - & & $\mathrm{mg} \mathrm{N} / \mathrm{L}$ & 1 & 22 & 23 & 18 & 24 & 20 & 13 & 13 & 13 \\
\hline Sólidos totais & - & & $\mathrm{mg} / \mathrm{L}$ & 134 & 4540 & 9390 & 300 & 342 & 330 & 234 & 310 & 366 \\
\hline $\begin{array}{l}\text { Sólidos dissolvidos } \\
\text { totais }\end{array}$ & $\leq 500$ & & $\mathrm{mg} / \mathrm{L}$ & 122 & 2040 & 8410 & 302 & 320 & 322 & 234 & 306 & 348 \\
\hline $\begin{array}{l}\text { Condutividade a } \\
25^{\circ} \mathrm{C}\end{array}$ & - & & $\mu \mathrm{mhos} / \mathrm{cm}$ & 227,5 & 3920 & 10170 & 583 & 633 & 614 & 380 & 529 & 627 \\
\hline Salinidade & - & & $\%$ & 0,1 & 2,2 & 6,0 & 0,3 & 0,3 & 0,3 & 0,2 & 0,3 & 0,3 \\
\hline Nitrogênio Nitrato & $\leq 10$ & $\leq 0,4$ & $\begin{array}{l}\mathrm{mg} \mathrm{N-} \\
\mathrm{NO}_{3} / \mathrm{L}\end{array}$ & $<0,02$ & 0,07 & $<0,02$ & $<0,02$ & $<0,02$ & $<0,02$ & $<0,02$ & $<0,02$ & $<0,02$ \\
\hline Fósforo Total & $\begin{array}{l}\leq 0,03 \text { (Lêntico) } \\
\leq 0,1 \text { (Lótico) }\end{array}$ & $\leq 0,124$ & $\mathrm{mg} \mathrm{P} / \mathrm{L}$ & 0,07 & 1,26 & 2,29 & 2,02 & 2,49 & 2,10 & 0,60 & 0,54 & 0,74 \\
\hline
\end{tabular}

Nota: Os valores em vermelho apresentados na tabela acima se referem às violações aos padrões da Resolução CONAMA $n^{\circ}$. 357/05, águas doces Classe 2. 


\section{REFERÊNCIAS}

BAHIA. Decreto 7596 de 05 de Junho de 1999. Cria a Área de Proteção Ambiental APA - de Joanes-Ipitanga e dá outras providências. Governo do Estado da Bahia, 1999.

BAHIA. Lei no $\mathbf{3 . 8 5 8}$ de 03 de novembro de 1980. Institui o Sistema Estadual de Administração dos Recursos Ambientais e dá outras providências. Governo do Estado da Bahia, 1980.

BRASIL. Lei 9.433 de 08 de janeiro de 1997. Institui a Política Nacional de Recursos Hídricos, que cria o Sistema Nacional de Gerenciamento de Recursos Hídricos. Brasília: Secretaria de Recursos Hídricos, Ministério do Meio Ambiente dos Recursos Hídricos e da Amazônia Legal, 1997.

Resolução CONAMA n 357 , de 17 de março de 2005. Dispõe sobre a classificação dos corpos de água e diretrizes ambientais para 0 seu enquadramento, bem como estabelece as condições e padrões de lançamento de efluentes, e dá outras providências. Conselho Nacional do Meio Ambiente, Brasília. Diário Oficial da União de 17 de março de 2005.

CETESB. Relatório de Qualidade das Águas Interiores no Estado de São Paulo: 2006. (Série Relatórios). São Paulo: Cetesb, Governo do Estado de São Paulo, 2007.

GOOGLE EARTH. Google Eart Explore, Search and Discover [computer program], Version 3.0 - Public Beta. Califórnia (USA); Imagens por satélite, 2015.
INEMA - Instituto do Meio Ambiente e Recursos Hídricos. Diagnóstico da Qualidade ambiental dos Rios de Salvador. Salvador: INEMA, 2013/2014.

LAMPARELLI, M. C.. Grau de trofia em corpos d'água do estado de São Paulo: avaliação dos métodos de monitoramento. 2004. 235 f. Tese (Doutorado) Departamento de Ecologia, Universidade de São Paulo, São Paulo, 2004.

MACHADO, P. A. L. Recursos hídricos: Direito Brasileiro e Internacional. São Paulo: Malheiros, 2002.

ONU. Assembleia Geral das Nações Unidas. Declaração da "ONU Água" para o Dia Mundial da Água, 2010. Disponível em:

$<$ https://nacoesunidas.org/acao/agua/>. Acesso em: 23 mar. 2018.

ROSSI, W.; BRANCO, L. C.; LACERDA, J. A.; GOMES, A. C.; WAGNER, E. M. S. Fontes de poluição e o controle da degradação ambiental dos rios urbanos em Salvador. Revista Interdisciplinar de Gestão Social - RIGS, n. 1, p. 63, 2012.

SALVADOR. Decreto no 19.752/2009. Cria o Parque Municipal do Manguezal do Rio Passa Vaca e dá outras providências. Diário Oficial do Município de Salvador, 2009, Salvador-BA. 14 de Julho de 2009.

SANTOS E.; PINHO J. A. G.; MORAES L. R. S.; FISCHER T. O caminho das águas em Salvador - Bacias Hidrográficas, Bairros e Fontes. Salvador-Ba: UFBA 2010.

ZEITUM, P. H. Water in crisis: a guide to the world's fresh water resources. Oxford: Oxford University Press, Inc., 2009. 